\title{
Design of Lewis-acid centres in zeolitic matrices for the conversion of renewables
}

\section{Review Article}

Author(s):

Dapsens, Pierre Y.; Mondelli, Cecilia; Pérez-Ramírez, Javier

Publication date:

2015-10-21

Permanent link:

https://doi.org/10.3929/ethz-a-010792792

Rights / license:

In Copyright - Non-Commercial Use Permitted

Originally published in:

Chemical Society Reviews 44(20), https://doi.org/10.1039/c5cs00028a

\section{Funding acknowledgement:}

140496 - Biomass to chemicals over tailored hierarchical zeolite-based catalysts (SNF) 


\title{
Design of Lewis-acid centres in zeolitic matrices for the conversion of renewables
}

\author{
Pierre Y. Dapsens, Cecilia Mondelli and Javier Pérez-Ramírez* \\ Received (in $X X X, X X X)$ Xth $X X X X X X X X X 20 X X$, Accepted Xth $X X X X X X X X X 20 X X$ \\ ${ }_{5}$ DOI: 10.1039/b000000x
}

The catalytic conversion of renewable feedstocks into chemicals is pursued as a means to sustainably fulfil future societal needs. Due to the oxygen-rich nature of bio-derived substrates, isomerisation, transfer-hydrogenation and retro-aldol reactions have emerged as relevant transformations to produce commodity chemicals and polymer building blocks. In this context, porous materials containing Lewis-

10 acid metals (e.g., Al, Ga, Sn, Ti, Zr) play an important role. Among these, tin-containing zeolites have demonstrated superior catalytic properties which have mainly been attributed to their hydrophobicity and crystallinity. This review evaluates the versatility and scalability of bottom-up and top-down approaches to introduce Lewis-acid functionalities in zeolitic matrices. A precise characterisation is shown to be crucial to determine the structure, acidity and environment of the sites introduced. In this regard, we

15 highlight the limitations of conventional techniques and the advantages of analytical and modelling tools recently applied to gain an improved understanding of these solids. Thereafter, property-performance relations and important aspects for the industrial amenability of new synthetic routes are exemplified through case studies. Finally, we put forward the need of gathering a deeper knowledge on the site location, surface properties and stability to aid the design of next-generation Lewis-acid catalysts.

\section{1. Introduction}

Over the last decade, remarkable efforts have been directed towards the development of sustainable catalytic routes to convert renewable (e.g., lignocellulose, terpenes, proteins) and waste (e.g., glycerol) feedstocks into valuable products in view of 25 addressing the forthcoming oil shortage, mitigate global warming and meet the consumers' demand for greener products.[1-5] While the biorefinery concept aiming at producing both fuels and chemicals in small and decentralised facilities has been the main driving force of research,[6] the discovery and recent policy 30 regarding shale gas and related tight oil utilisation is definitively changing the picture. In fact, the exploitation of this abundant fossil feedstock may in the long term hamper the large-scale production of biofuels. With respect to chemicals, while shale gas might represent a more convenient source of light hydrocarbons,

35 building blocks such as butadiene, benzene, toluene and xylenes could still be more conveniently produced from biomass.[7] Besides, relevant oxygenated chemicals with no petroleumderived analogues can be also generated from bio-derived feedstocks by means of eco-efficient transformations. These 40 comprise $\alpha$-hydroxyacids (lactic acid, glycolic acid), [8,9] which are already produced at a large scale, and furan-derivatives, which hold great potential for application in the polymer industry, as exemplified by the envisaged partial replacement of terephtalic acid by furan-2,5-dicarboxylic acid.[10-13]

45 Owing to the high oxygen content in biomass and the need to control its intrinsic reactivity, liquid-phase transformations at mild temperatures (353-453 K) are often practiced. This forces scientists to reassess the catalyst box so far developed for the gasphase valorisation of petrol.[4,14] Owing to their versatility,[15] 50 zeolite and zeotype-based catalysts are expected to play a prominent role in the valorisation of renewables.[16,17] Nevertheless, Lewis-acid zeolites (i.e., Sn-BEA) have demonstrated more efficient compared to amorphous porous materials (i.e., Sn-MCM-41, Sn-SBA-15) in relevant hexoses and 55 trioses conversions, especially in aqueous media (Fig. 1).[18] Their activity in water is surprising, considering the hard Lewisbasic character of this solvent which tends to inhibit the active centres by competitive adsorption.[19] In this respect, it is believed that the intrinsic hydrophobicity of the zeolite surface 60 plays a critically beneficial role, albeit the influence of crystallinity and site speciation cannot be excluded.[20]

Traditionally, Lewis acidity in zeolites originates from the presence of extraframework aluminium species (EFAl). Its interplay with Brønsted acidity has proved of crucial 65 importance,[21] as exemplified by the FCC process in which Lewis acidity generates carbenium anions by hydride abstraction, therefore favouring cracking reactions.[22] As demonstrated 3 decades ago by Enichem, strong and isolated Lewis-acid sites can also be generated by the isomorphic substitution of silicon by a 70 metal (e.g., Ti, Zr, Sn) in a pure-silica framework, with TS-1 (MFI framework) as the most prominent example.[23] Noteworthy, those catalysts have been primarily used for their redox properties in the production of fine chemicals.[24] The 


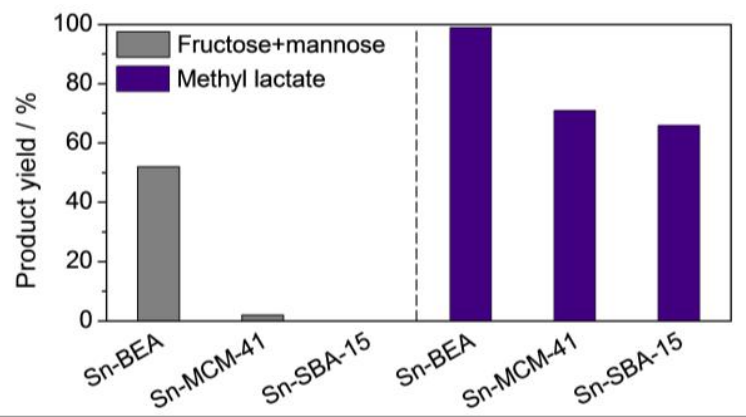

Fig. 1 Isomerisation of glucose and dihydroxyacetone in water and methanol, respectively, over tin-containing porous materials. Adapted from 18 .

transition from these $\mathrm{H}_{2} \mathrm{O}_{2}$-mediated oxidations to Lewis-acid 5 catalysed conversions of biobased bulk chemicals has been recently put in perspective by Moliner.[25] Nonetheless, due to the rapid evolution of the field, the scope of reactions therein reported has already been broadened by further biobased transformations catalysed by a new wave of Lewis-acid solids 10 obtained by post-synthetic methods and novel bottom-up procedures (Table 1). This recent exploration of alternative synthetic approaches has been mainly motivated by the limited industrial amenability of the hydrothermal synthesis of the most widely applied Lewis-acid zeolite, i.e., Sn-beta. Still, a systematic 15 and critical evaluation of their potential for large-scale implementation is hardly presented. Furthermore, they have been rarely put face to face with hydrothermal synthesis in order to identify their peculiarities in terms of structure, acid strength and placement of the metal sites introduced. In this context, state-of20 the-art analytic techniques are being re-assessed and new methodologies being developed to help the characterisation of these centres.

This review aims at discussing the current status of zeolitebased Lewis-acid catalysis for the production of renewables and 25 it is structured as follows. Initially, it describes the methods to produce Lewis-acid zeolites, viz. the classical hydrothermal synthesis, the dry-gel conversion methods and post-synthetic approaches, critically discussing the poorly addressed aspects of applied and fundamental relevance mentioned above. Thereafter, 30 it illustrates the characterisation techniques that can be applied to probe the nature, structure and location of the Lewis-acid centres introduced in the zeolites, pointing out the sometimes limited reliability of the information gathered by traditional methods and highlighting the advantages of newly developed analytical tools. 35 Thereafter, it covers three specific examples delineating how control on activity and selectivity can be achieved by tuning the nature, speciation and amount of Lewis-acid sites and a recent attempt made to identify factors at the catalyst and process level which crucially impact on the viability of an emerging biobased 40 route. Finally, it provides an outlook on research directions that should be prioritised in the near- term to enable a better link between synthesis, property and performance, which is imperative to ultimately design improved catalytic systems of industrial relevance.

45

\section{Synthesis of Lewis-acid zeolites}

\section{${ }_{50}$ 2.1. Bottom-up approaches}

\subsubsection{Hydrothermal synthesis}

Purely microporous zeolites

The development of Lewis-acid zeolites is closely related to the synthesis of titanium silicalite- 1 and to the demonstration that all55 silica zeolites could also be crystallised under near neutral conditions using fluoride ions as mineralising agent,[26,27] which opened the door to the addition of metal precursors that are not or poorly soluble in basic media. While materials containing various Lewis-acid metals (e.g., Sn, Zr, Hf) have been prepared, ${ }_{60}$ only works focusing on Sn-substituted zeolites will be herein discussed. Indeed, the hydrothermal synthesis of Ti-containing porous materials has been recently reviewed by Moliner and Corma [28] and Sn-containing zeolites have proved as the most active Lewis-acid catalysts, as reported in Table 1. It is worth 65 noting that the preparation of zeolites applied in traditional oxidation processes will be reviewed too, since framework insertion of tin is a prerequisite of both a good redox and Lewisacid catalyst.

MFI topology. Owing to the facile and rapid synthesis of 70 silicalite-1, the isomorphous framework substitution of Si by $\mathrm{Sn}$ was first attempted within the MFI structure (Sn-MFI).[29] Zeolites with $\mathrm{Si} / \mathrm{Sn}$ ratios between 33 and 133 were produced. Based on textural and structural characterisation by multiple techniques and catalytic tests in the hydroxylation of phenol, it 75 was shown that tin was effectively incorporated into the framework only for materials featuring a ratio higher than 40, while extraframework hexacoordinated species were formed in the presence of greater Lewis-acid metal contents. Mal et al. [30] evidenced that the order upon which the silica and tin sources and 80 the structure-directing agent were added in the preparation of the synthesis gel does not significantly impact the $\mathrm{Si} / \mathrm{Sn}$ ratio in the final material but strongly affects the crystallinity, grain size and Sn speciation (Fig. 2). In particular, large particles displaying poor crystallinity and a considerable amount of $\mathrm{SnO}_{2}$ were ${ }_{85}$ formed when $\mathrm{SnCl}_{4}$ was added as last. In this situation, silicon polymerisation likely is advanced when the tin source is introduced and the Lewis-acid metal cannot be fully integrated into the structure. This material displayed a scarce activity in the $\mathrm{H}_{2} \mathrm{O}_{2}$-mediated hydroxylation of phenol. Interestingly, an even 90 poorer performance was shown by a zeolite synthesised in fluoride media according to the route established by Costantini et al. [31] which, taking into account the bulkiness of the substrate, was ascribed to the large crystal size of this zeolite. Recently, SnMFI zeolites ( $c a .1 .5 \mathrm{wt} . \% \mathrm{Sn}$ ) prepared in hydroxide media and ${ }_{95}$ featuring framework tin sites demonstrated very active and selective in the isomerisation of biobased glyoxal and dihydroxyacetone (DHA) to glycolic and lactic acid and their ethyl ester derivatives.[32,33]

BEA topology. The synthesis of Sn-BEA is directly linked to 100 the synthesis of all-silica BEA which has been a topic of strong interest in the 90 s owing to the peculiar kinetics of crystallisation of this zeolite. For a long time, it was assumed that BEA could not nucleate (but could still grow) in the absence of trivalent metallic atoms such as $\mathrm{Al}^{3+}$ or $\mathrm{B}^{3+}$.[34] While this can be 105 exploited to produce bifunctional catalysts,[35] it comprises 
Table 1 Applications of Lewis-acid zeolites for the conversion of renewables to chemicals

\begin{tabular}{|c|c|c|c|c|c|c|c|}
\hline $\begin{array}{l}\text { Nature of } \\
\text { transformation }\end{array}$ & Reactant $^{a}$ & Product & Catalyst $^{b}$ & Conditions $^{c}$ & $\begin{array}{l}X_{\text {reactant }}{ }^{c} \\
(\%)\end{array}$ & $\begin{array}{l}Y_{\text {product }}{ }^{c} \\
(\%)\end{array}$ & References \\
\hline \multirow{22}{*}{ 1,2-H shift } & \multirow[t]{2}{*}{ Glyceraldehyde } & \multirow[t]{2}{*}{ Dihydroxyacetone } & Sn-BEA & $\mathrm{H}_{2} \mathrm{O}, 363 \mathrm{~K}, 2 \mathrm{~h}$ & n.a. & 95 & 36 \\
\hline & & & Ti-BEA & $\mathrm{H}_{2} \mathrm{O}, 363 \mathrm{~K}, 2 \mathrm{~h}$ & n.a. & 19 & 36 \\
\hline & \multirow[t]{2}{*}{ Glyoxal } & \multirow[t]{2}{*}{ Glycolic acid } & USY & $\mathrm{H}_{2} \mathrm{O}, 363 \mathrm{~K}, 18 \mathrm{~h}$ & 62 & 57 & 32 \\
\hline & & & GaUSY & $\mathrm{H}_{2} \mathrm{O}, 363 \mathrm{~K}, 18 \mathrm{~h}$ & 80 & 77 & 32 \\
\hline & Cortalcerone & Furylglycolic acid & Al-Sn-BEA ${ }^{\dagger}$ & $\mathrm{H}_{2} \mathrm{O} / \mathrm{MeOH}, 358 \mathrm{~K}, 0.5 \mathrm{~h}$ & 53 & 22 & 35 \\
\hline & \multirow[t]{8}{*}{ Dihydroxyacetone } & \multirow[t]{5}{*}{ Lactic acid } & Sn-MFI ${ }^{\dagger}$ & $\mathrm{H}_{2} \mathrm{O}, 413 \mathrm{~K}, 1 \mathrm{~h}$ & 100 & 93 & $18,33,37$ \\
\hline & & & Sn-BEA & $\mathrm{H}_{2} \mathrm{O}, 398 \mathrm{~K}, 24 \mathrm{~h}$ & 100 & 90 & $18,37,38,39$ \\
\hline & & & Sn-MWW ${ }^{\dagger}$ & $\mathrm{H}_{2} \mathrm{O}, 383 \mathrm{~K}, 6 \mathrm{~h}$ & 100 & 96 & 39 \\
\hline & & & $\mathrm{USY}^{\ddagger}$ & $\mathrm{H}_{2} \mathrm{O}, 398 \mathrm{~K}, 24 \mathrm{~h}$ & 100 & 71 & 40 \\
\hline & & & Hierarchical ZSM-5 & $\mathrm{H}_{2} \mathrm{O}, 413 \mathrm{~K}, 6 \mathrm{~h}$ & 91 & 83 & 41 \\
\hline & & \multirow{3}{*}{ Alkyl lactates } & $\mathrm{Sn}-\mathrm{MFI}^{\dagger,+}$ & $\mathrm{MeOH}, 413 \mathrm{~K}, 1 \mathrm{~h}$ & & & 33 \\
\hline & & & GaUSY $^{\dagger}$ & $\mathrm{EtOH}, 358 \mathrm{~K}, 24 \mathrm{~h}$ & 99 & 82 & 32,46 \\
\hline & & & Hierarchical TS- $1^{\dagger}$ & EtOH, 378 K, 6 h & 49 & 47 & 47 \\
\hline & Erythrose & Erythrulose & $\mathrm{USY}^{\dagger}$ & $\mathrm{H}_{2} \mathrm{O}, 393 \mathrm{~K}, 5 \mathrm{~h}$ & 68 & 45 & 48 \\
\hline & Arabinose & Ribulose & Sn-BEA & $\mathrm{H}_{2} \mathrm{O}, 358 \mathrm{~K}, 0.5 \mathrm{~h}$ & 30 & 11 & 49 \\
\hline & \multirow[t]{4}{*}{ Xylose } & \multirow[t]{4}{*}{ Xylulose } & Sn-BEA & $\mathrm{H}_{2} \mathrm{O}, 373 \mathrm{~K}, 0.25 \mathrm{~h}$ & 60 & 27 & $37,49,50$ \\
\hline & & & Sn-MFI & $\mathrm{H}_{2} \mathrm{O}, 363 \mathrm{~K}, 3.5 \mathrm{~h}$ & 40 & 19 & $14,37,51$ \\
\hline & & & Hierarchical Sn-MFI & $\mathrm{H}_{2} \mathrm{O}, 353 \mathrm{~K}, 2 \mathrm{~h}$ & 22 & $7^{a}$ & 18,52 \\
\hline & & & $\mathrm{USY}^{\dagger}$ & $\begin{array}{l}\mathrm{MeOH}, 373 \mathrm{~K}, 1 \mathrm{~h} \\
\text { then } \mathrm{H}_{2} \mathrm{O}, 373 \mathrm{~K}, 1 \mathrm{~h}\end{array}$ & 69 & 47 & 53 \\
\hline & Galactose & Tagatose & Sn-BEA & $\mathrm{H}_{2} \mathrm{O}, 383 \mathrm{~K}, 2 \mathrm{~h}$ & 38 & 25 & 17 \\
\hline & Glucose & Fructose & Sn-BEA & $\mathrm{H}_{2} \mathrm{O}, 383 \mathrm{~K}, 0.5 \mathrm{~h}$ & 55 & 32 & $\begin{array}{l}15,37,18,49,54 \\
55,56,57,58,59 \\
60\end{array}$ \\
\hline & Lactose & Lactulose & Hierarchical Sn-MFI & $\mathrm{H}_{2} \mathrm{O}, 353 \mathrm{~K}, 2 \mathrm{~h}$ & 29 & 24 & 18 \\
\hline $\begin{array}{l}\text { Oxidation } \\
+1,2-\mathrm{H} \text { shift } \\
\end{array}$ & Glycerol & Lactic acid & $\mathrm{Pt} / \mathrm{Sn}-\mathrm{MFI}$ & $\begin{array}{l}\mathrm{H}_{2} \mathrm{O}, 373 \mathrm{~K}, 24 \mathrm{~h} \\
\mathrm{O}_{2}=0.62 \mathrm{MPa}\end{array}$ & 90 & 72 & 62 \\
\hline \multirow{6}{*}{ 1,2-C shift } & \multirow[t]{3}{*}{ Glucose } & \multirow[t]{3}{*}{ Mannose } & Sn-BEA & $\mathrm{MeOH}, 333-373 \mathrm{~K}$ & n.a. & n.a & 63 \\
\hline & & & Na-Sn-BEA & $\mathrm{MeOH}, 353 \mathrm{~K}, 0.5 \mathrm{~h}$ & 12 & 8 & 64 \\
\hline & & & Sn-BEA+borate salts & $\mathrm{H}_{2} \mathrm{O}, 358 \mathrm{~K}, 1 \mathrm{~h}$ & 31 & 27 & 49 \\
\hline & \multirow[t]{2}{*}{ Xylose } & Lyxose & Sn-BEA & $\mathrm{H}_{2} \mathrm{O}, 383 \mathrm{~K}, 2 \mathrm{~h}$ & 61 & 35 & 17 \\
\hline & & & Sn-BEA+borate salts & $\mathrm{H}_{2} \mathrm{O}, 358 \mathrm{~K}, 0.25 \mathrm{~h}$ & 30 & 26 & 49 \\
\hline & Arabinose & Ribose & Sn-BEA+borate salts & $\mathrm{H}_{2} \mathrm{O}, 358 \mathrm{~K}, 0.25 \mathrm{~h}$ & 34 & 33 & 49,65 \\
\hline $1,5-\mathrm{H}$ shift & Glucose & Sorbose & Ti-BEA & $\mathrm{MeOH}, 373 \mathrm{~K}, 2 \mathrm{~h}$ & 36 & 12 & 58,66 \\
\hline & Sugars & Methyl lactate & $\mathrm{Sn}_{-\mathrm{BEA}^{\dagger}}^{\dagger}$ & $\mathrm{MeOH}, 433 \mathrm{~K}, 20 \mathrm{~h}$ & 100 & 64 & $18,67,68$ \\
\hline & & & Sn-BEA+alkali salts & $\mathrm{MeOH}, 443 \mathrm{~K}, 16 \mathrm{~h}$ & 100 & 75 & 69 \\
\hline (Retro)- & & & Sn-MWW & $\mathrm{MeOH}, 433 \mathrm{~K}, 20 \mathrm{~h}$ & 100 & 50 & 39 \\
\hline & $\begin{array}{l}\text { Dihydroxyacetone+ } \\
\text { Formaldehyde }\end{array}$ & $\begin{array}{l}\alpha \text {-Hydroxy- } \gamma \text { - } \\
\text { butyrolactone }\end{array}$ & Sn-BEA & Dioxane, $433 \mathrm{~K}, 3 \mathrm{~h}$ & 98 & 60 & 70 \\
\hline & 5-HMF & Furan derivatives & Sn-BEA & $i$-PrOH, $453 \mathrm{~K}, 6 \mathrm{~h}$ & 92 & 87 & 71 \\
\hline & & & Sn-BEA ${ }^{\ddagger}$ & EtOH. 393 K, 24 h & 69 & 41 & 72 \\
\hline & & & $\mathrm{Zr}-\mathrm{BEA}$ & EtOH. 393 K, 24 h & 81 & 54 & 72 \\
\hline H-transfer & & & Ti-BEA & EtOH. 393 K, 24 h & 16 & 0 & 72 \\
\hline with solvent as & & & Hf-BEA & EtOH. 393 K, 24 h & 87 & 67 & 72 \\
\hline & & & $\mathrm{Nb}-\mathrm{BEA}$ & EtOH. 393 K, 24 h & 31 & 3 & 72 \\
\hline & & & Ta-BEA & EtOH. 393 K, 24 h & 85 & 2 & 72 \\
\hline
\end{tabular}




\begin{tabular}{|c|c|c|c|c|c|c|}
\hline \multirow{4}{*}{$\begin{array}{l}\text { Diels-Alder } \\
\text { cycloaddition } \\
+ \text { dehydration }\end{array}$} & \multirow{4}{*}{$\begin{array}{l}\text { Furan derivative } \\
+ \text { ethylene }\end{array}$} & \multirow{4}{*}{$\begin{aligned} & p \text {-Xylene derivative } \text { Sn-MFI } \\
& \text { Sn-BEA } \\
& \text { Zr-BEA }\end{aligned}$} & Dioxane, $463 \mathrm{~K}, 6 \mathrm{~h}$ & 9 & 1 & 75 \\
\hline & & & Dioxane, $463 \mathrm{~K}, 6 \mathrm{~h}$ & 50 & 24 & 75 \\
\hline & & & Dioxane, $463 \mathrm{~K}, 6 \mathrm{~h}$ & 26 & 21 & 75 \\
\hline & & & Dioxane, $463 \mathrm{~K}, 12 \mathrm{~h}$ & 2 & 1 & 75 \\
\hline
\end{tabular}

${ }^{a}$ Feed concentration in the range of 3-10 wt.\%. ${ }^{b}$ The catalysts that proved reusable at least 2 times and the one evaluated under flow -operation are marked with $\dagger$ and $\ddagger$, respectively. ${ }^{c}$ Based on the highest yield reported in literature.

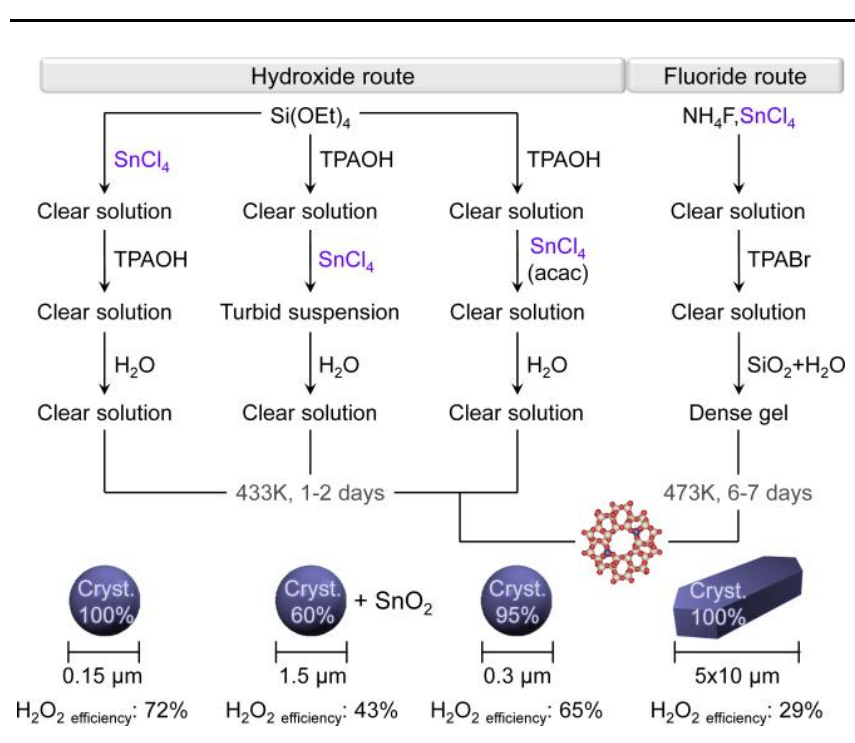

Fig. 2 Procedures for the preparation of Sn-MFI zeolites and their impact 5 on the morphology, Sn speciation and catalytic activity. Adapted from ref. 30 .

a major hurdle for the preparation of highly selective Brønstedacid-free catalysts, considering that $\mathrm{Al}$ tends to incorporate more easily into the framework compared to Sn.[76] In this context, 10 van der Waal et al. [77] demonstrated that nucleation of all-silica beta could be induced adding to the gel seeds of boron-containing beta that was subjected to demetallation by acid treatment. Following a seed-assisted approach, Mal et al. [76] attempted the hydrothermal conversion of a stannosilicate gel (basic media, $15415 \mathrm{~K}, 10 \mathrm{~h})$. The resulting $\mathrm{Sn}-\mathrm{BEA}(\mathrm{Si} / \mathrm{Sn}=85)$ featured small $(300 \mathrm{~nm})$ particles containing framework tin species but displaying a crystallinity of only $67 \%$. A highly crystalline and defect-free $\mathrm{Sn}-\mathrm{BEA}(\mathrm{Si} / \mathrm{Sn}=125)$ was later attained by Corma $e t$ al. [78] applying the fluoride-mediated procedure introduced in 201996 by Camblor et al. [27] for the preparation of pure-silica BEA (60 rpm, $413 \mathrm{~K}$ ) but using seeds and allowing for a longer crystallisation time (20 days instead of $39 \mathrm{~h}$ ). Sn-beta zeolites prepared using this protocol or analogous seedless procedures displayed outstanding performance in the isomerisation of 25 glucose to fructose [55] and mannose,[49,64] xylose to xylulose,[50] lactose to lactulose,[58] DHA to lactic acid and alkyl lactates,[38] in the one-pot conversion of glucose to lactic acid (through consecutive isomerisation-retroaldol reactionisomerisation),[67] in the conversion of 5-HMF into furan 30 derivatives[71,72], furan into $p$-xylene-[75] and in the C-C coupling between DHA and formaldehyde.[70] Tolborg et al. [79] recently evaluated the impact of the amount and nature of the tin precursor in the gel on the kinetics of crystallisation, the tin distribution and the crystal morphology. The authors revealed 35 that a progressive increase in the tin content $(0,1$ and $1.8 \mathrm{wt} . \%)$ led to an increase in the crystallisation time (4, 7 and 60 days, respectively). The materials obtained featured very similar textural properties but very different crystal morphology. The latter evolved from the typical capped square bipyramidal shape 40 to plates upon decreasing $\mathrm{Si} / \mathrm{Sn}$ ratio (Fig. 3). For a defined $\mathrm{Si} / \mathrm{Sn}$ ratio, a longer crystallisation time only led to crystals of larger size but their shape was retained. Interestingly, the metal did not distribute evenly and higher tin concentrations were observed at the outer shell of the crystals regardless of the $\mathrm{Si} / \mathrm{Sn}$ ratio. ${ }_{45}$ Catalytic testing of the conversion of DHA into methyl lactate over solids obtained at variable crystallisation time identified a clear dependence of the product yield on the crystallinity but no apparent contribution of the crystal shape. Overall, catalysts with a $\mathrm{Si} / \mathrm{Sn}$ ratio below 200 (1 wt.\%) were extremely active.

${ }_{50}$ In view of a prospective industrial application, one key aspect to be discussed is the scalability of the zeolite manufacture. In this respect, Sn-MFI appears as a more viable material than SnBEA. As described above, the former can be readily produced in hydroxide media. This is similar to the case of TS-1, which has 55 been manufactured by EniChem for over 3 decades.[23] In contrast, the synthesis of Sn-BEA is long and relies on the use of HF. While the first characteristic may not be critical and seeds can be applied to reduce the aging time, owing to the corrosive nature of the mineralising agent, significant investment costs will ${ }_{60}$ be necessary in order to retrofit the current zeolite manufacturing facilities. In addition, the noxious nature of fluoride ions imposes to comply with strict safety protocols. Accordingly, a large-scale
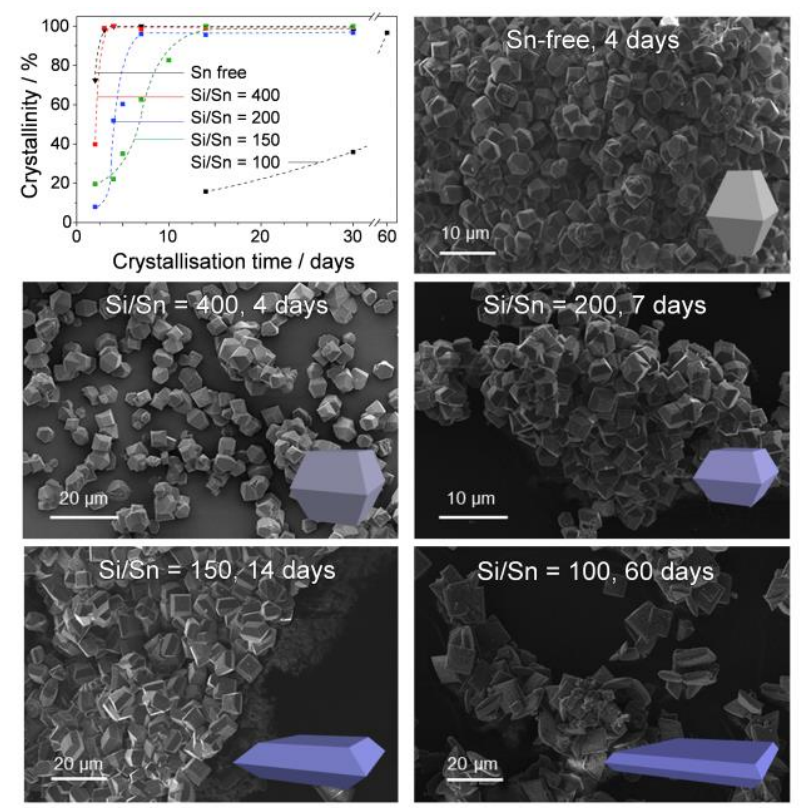

Fig. 3 Evolution of the crystallinity of Sn-BEA zeolites with the duration of the hydrothermal synthesis from gels with different $\mathrm{Si} / \mathrm{Sn}$ ratios and ${ }_{65}$ SEM imaging identifying the distinct particle morphology. Adapted from ref. 79. 
a)

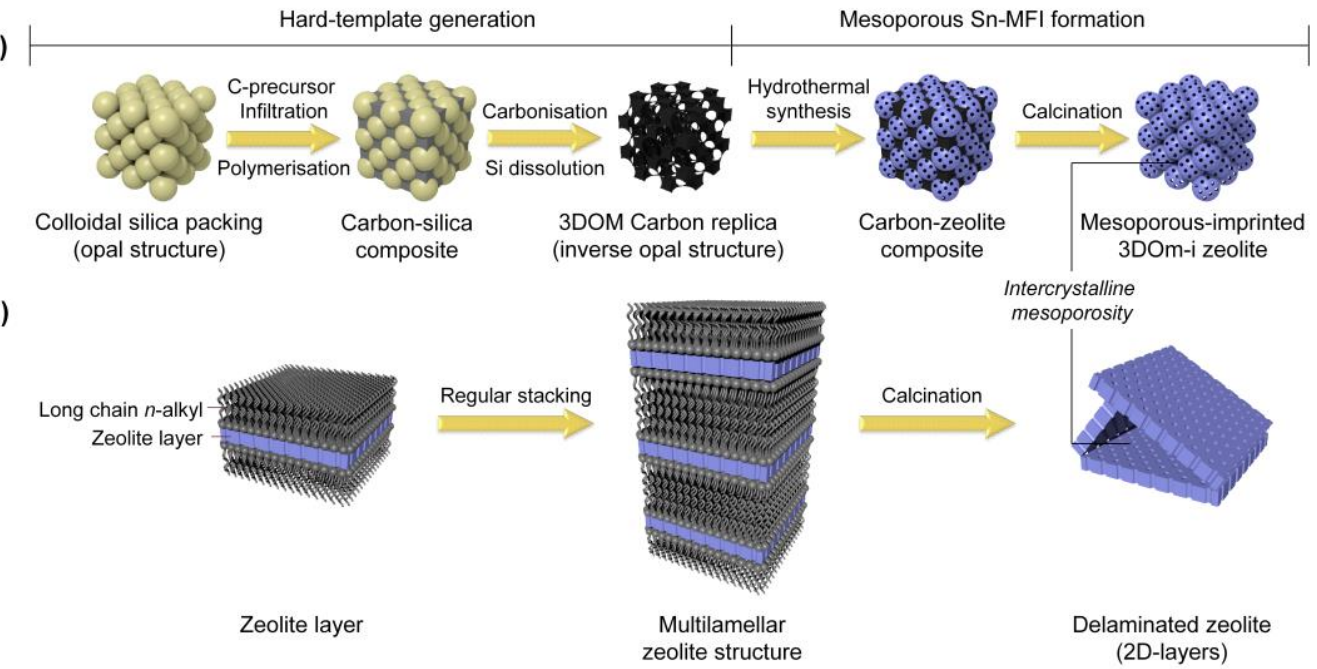

Fig. 4 Bottom-up approaches for the preparation of hierarchical tin-containing zeolites using a (a) hard or (b) soft template.

production of Sn-BEA would only be considered if the peculiar 5 nature of this material renders it as a truly unique catalyst for the production of added-value products.

Other topologies. Although BEA and MFI frameworks have received significant attention for the conversion of renewables, the incorporation of metals in other zeolite framework topologies 10 has also been attempted. The so-called high-silica pentasil zeolites have been particularly investigated. Thus, Mal et al. successfully prepared isomorphously substituted Sn-MEL $(\mathrm{Si} / \mathrm{Sn}=40-100)[80]$ and $\mathrm{Sn}-\mathrm{MTW}(\mathrm{Si} / \mathrm{Sn}=75-180)$ [81] based on the protocols developed for the preparation of all-silica ZSM-

1511 (silicalite-2) [82] and ZSM-12.[83] These materials exhibited comparable $\mathrm{H}_{2} \mathrm{O}_{2}$ efficiency in the hydroxylation of aromatics with respect to Sn-MFI. Since the synthesis method of Sn-MEL and Sn-MTW is rather equivalent to that of Sn-MFI, the comments made above with respect to industrially-relevant 20 aspects of the synthesis and properties of Sn-MFI should hold also for these zeolites.

\section{Hierarchical zeolites}

The intrinsic property of zeolites to possess pores of size close to that of molecules, enabling shape selectivity, is also one of their 25 main disadvantages, since it often implies diffusion limitations.[84,85] Accordingly, the preparation of materials displaying an additional level of porosity (meso- or macroporosity) besides microporosity is a topic of great interest.[15,86,87,88] Two main classes of methodologies, i.e., 30 bottom-up or top-down, have been developed for the synthesis of hierarchical aluminosilicate zeolites.[89] Both approaches have been explored to generate mesoporous Lewis-acid zeolites. Bottom-up strategies will be hereon reviewed whereas top-down approaches will be discussed in section 2.2.1.

35 The group of Fan [52] generated mesoporous Sn-MFI $(\mathrm{Si} / \mathrm{Sn}=125)$ by confined growth in a hard template consisting of a three-dimensionally ordered mesoporous (3DOm) carbon placed in the synthesis gel (Fig. 4a). Following a typical protocol, the $3 \mathrm{DOm}$ carbon was prepared by $(i)$ infiltration of a carbon 40 source (e.g., furfuryl alcohol, oxalic acid) into self-assembled silica spheres used as opal template, (ii) polymerisation and carbonisation of the carbon source and finally (iii) silica dissolution with $\mathrm{KOH}$.[90] The resulting zeolite was proved to be hierarchical, small-sized and to feature framework Sn atoms. ${ }_{45}$ While the presence of interconnected mesoporosity did not lead to any advantage in the isomerisation of a diffusion-free substrate like pyruvaldehyde, a 18 and 14 times higher turn-over frequency (TOF) was calculated for the conversion of the diffusion- and access- limited xylose and glucose, respectively, compared to 50 purely microporous Sn-MFI prepared in fluoride media. Notably, the use of carbon scaffolds for preparing multimodal porous structures has become a vibrant area of research owing to the versatility of the method enabling the tuning of the well-ordered mesopores produced in terms of size and shape.[91] Nevertheless, 55 an industrial implementation of this approach seems unlikely in view of its rather high complexity and the elevated cost.

Mesoporous Sn-MFI was alternatively prepared by Luo et al. [92] adapting a strategy developed by Choi et al. [93] that consisted in using a surfactant-like organic structure-directing 60 agent comprising a hydrophobic tail and a hydrophilic head (Fig. 4b). The authors found a strong influence of the tin content as well as the nature of the metal precursor on the properties of the final material. In particular, the use of tin butoxide unavoidably led to the formation of $\mathrm{SnO}_{x}$ clusters even for high ${ }_{65} \mathrm{Si} / \mathrm{Sn}$ ratios ( $\left.c a .250\right)$. Tin chloride enabled the insertion of the metal in the framework, but, for high concentrations in the gel $(\mathrm{Si} / \mathrm{Sn}=133)$, the crystallinity of the zeolite was inferior. The optimal hierarchical Sn-MFI, with mesopores in the range of 5$20 \mathrm{~nm}$, featured a $\mathrm{Si} / \mathrm{Sn}$ ratio of 167 and demonstrated highly 70 active in the $\mathrm{H}_{2} \mathrm{O}_{2}$-mediated oxidation of bulky ketones such as 2adamantanone. Still, the performance of this catalyst was inferior to the large-pore Sn-beta. One main intrinsic disadvantage of this method possibly is the demanding synthesis of the structuredirecting agent, which is not commercially available.

75 It is worth noting that only the generation of hierarchical SnMFI was attempted so far since the benefit of additional porosity levels is more prominent for medium compared to large-pore zeolites. Still, the methods introduced are likely applicable to 


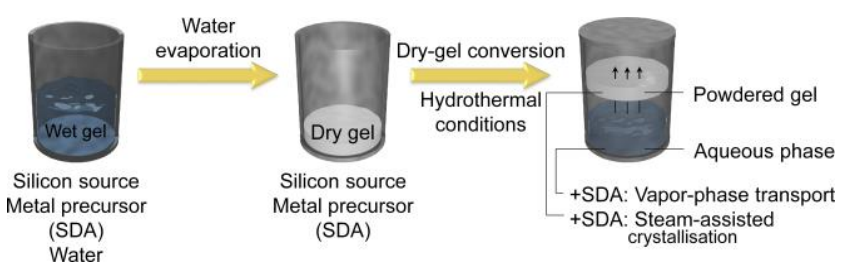

Fig. 5 Procedure for the synthesis of tin-containing zeolites by dry-gel conversion techniques.

other relevant frameworks, such as BEA, MTW and MEL.

\subsubsection{Dry-gel conversion techniques}

5 Dry-gel conversion techniques rely on the crystallisation of a dry and amorphous (metallo)silicate gel in the presence of vapour streams. Two methods are distinguished, i.e., vapour-phase transport (VPT) if the structure-directing agent is volatile or steam-assisted crystallisation (SAC) for non-volatile structure10 directing agents that are added to the gel (Fig. 5).[94] VPT using ethylenediamine was applied for the first time in 1990 to prepare ZSM-5 by $\mathrm{Xu}$ et al.[95] Later, other aluminosilicates including FAU, MOR and BEA have been obtained by this technique. SAC of Sn-MFI was reported by Niphadkar et al. [96] in 2009. 15 Performing syntheses at variable crystallisation time, temperature, $\mathrm{Si} / \mathrm{Sn}$ and $\mathrm{Si} / \mathrm{TPA}$ ratios as well as amount of water, the authors demonstrated that less structure-directing agent and shorter crystallisation times were required in SAC compared to the conventional hydrothermal synthesis route to obtain materials 20 with similar $\mathrm{Si} / \mathrm{Sn}$ ratio and catalytic properties. The alternative method also presents the advantage to minimise waste disposal and increase the solid yield of the synthesis.

The preparation of Sn-BEA was also recently investigated by SAC by Kang et al. [97] In contrast to the lengthy hydrothermal 25 synthesis, only $5 \mathrm{~h}$ were required to convert the amorphous stannosilicate gel $(\mathrm{Si} / \mathrm{Sn}=125)$ into a fully crystalline $\mathrm{Sn}$-BEA. Still, the use of HF remained a requirement. It is worth mentioning that this procedure was not effective in producing SnBEA zeolites from stannosilicate gels with $\mathrm{Si} / \mathrm{Sn}<75$ even after $30200 \mathrm{~h}$. This composition-related limitation is common to the hydrothermal synthesis and might imply that the parameters governing tin insertion in the framework are equivalent in dry-gel conversion techniques. Interestingly, Chang et al.[60] recently demonstrated that Sn-beta can be obtained by SAC in a caustic 35 rather than fluoride medium provided that seeds of zeolite beta are added to the gel. The as-synthesised solid has to be transformed into the protonic form prior to calcination to ensure the retention of the crystalline structure. The catalyst displayed lower and comparable activity in the isomerisation of glucose and 40 pyruvaldehyde, respectively, compared to hydrothermallyprepared Sn-beta. Reduced hydrophobicity and differences in the local environment of $\mathrm{Sn}$ were claimed as possible reasons for this discrepancy.

\subsection{Top-down approaches}

\section{${ }_{45}$ 2.2.1 Direct metallation}

The so-called 'atom-planting' method was the first strategy reported for the introduction of Lewis-acid metals in zeolitic matrices.[98] Following the studies by the group of Beyer [99] on the dealumination of ZSM-5 zeolites with silicon chloride
50 vapours, it was conceived to explore the opposite reaction, i.e., the alumination of highly siliceous zeolites with aluminium chlorides. In 1984, researchers at Mobil [100] demonstrated that treating high-silica ZSM-5 zeolites at $648 \mathrm{~K}$ in the presence of either $\mathrm{AlCl}_{3}$ or $\mathrm{AlBr}_{3}$ enables the direct insertion of aluminium 55 into the framework. Dessau and Kerr [101] showed in the same year that alumination with $\mathrm{AlCl}_{3}$ vapours can be successfully applied also to ZSM-11 zeolites at $773 \mathrm{~K}$. In both works, it was suggested that the metal integrates at defect sites, i.e., external and/or internal silanols, originally present in the zeolites. This 60 was corroborated by mechanistic studies of aluminium incorporation at variable temperature, partial pressure of $\mathrm{AlCl}_{3}$ and reaction time [102] in materials featuring distinct amounts of defect sites [103] and might explain the limited amount of aluminium incorporated in the treated samples (0.6-2.0 wt.\%). ${ }_{65}$ Alternatively, wet treatments with $\mathrm{AlF}_{3}$ were carried out. This effectively comprised the impregnation of silicalite-1 with an $\left(\mathrm{NH}_{4}\right)_{3} \mathrm{AlF}_{6}$ solution, followed by heating at $403 \mathrm{~K}$. In this case, due to the high reactivity of inorganic fluorides towards silica, it was supposed that alumination could proceed even in the absence

70 of defect sites in the zeolite. Yashima et al. [103] introduced also other metals than $\mathrm{Al}$, i.e., $\mathrm{Ti}, \mathrm{Sb}, \mathrm{Ga}$, In and As, into silicalite via vapour-phase reaction at $873-923 \mathrm{~K}$ and Skeels et al. [104] incorporated $\mathrm{Cr}$ and $\mathrm{Sn}$ in zeolite $\mathrm{Y}$ through treatment with the corresponding metal fluoride solutions, thus showing the 75 versatility of the strategies in terms of the nature of the metal that can be integrated. Besides, atom layer deposition, a technique based on the exposure of the material to sequential pulses of trimethylaluminium and water, has been exploited to introduce aluminium in various zeolites.[105,106,107,108] It should be 80 noted that all these methods generally aimed at increasing the Brønsted acidity of the catalysts to improve their efficiency in traditional acid-catalysed reactions such as cracking of $n$-hexane and octane or isomerisation and cracking of $n$-decane, but, since the incorporation of the metal ions into the framework was only 85 partially effective, Lewis-acidic metal species were also generated. However, the relative amount of Brønsted and Lewisacid sites was not determined. While being generated for specific fossil fuel-based applications (alkane aromatisation and propene dehydrogenation), it might be here worth recalling the synthesis 90 of gallium- and zinc-containing zeolites combining Brønsted- and Lewis-acid characters since they could possibly be extrapolated to emerging renewable routes in the future. Besides for hydrothermal synthesis, these metallosilicates are prepared by ion exchange, impregnation or chemical vapour deposition onto 95 ZSM-5, beta and mordenite zeolites and contain variable relative amounts of highly dispersed cations at ion exchange or framework (partial/full incorporation) positions, $\mathrm{GaO}^{+},\left(\mathrm{Ga}_{x} \mathrm{O}_{x}\right)^{x+}$ (with $x=2,4$ ) species at ion exchange positions, extraframework $\mathrm{GaO}_{x}$ and $\mathrm{ZnO}_{x}$ clusters and $\mathrm{Ga}_{2} \mathrm{O}_{3}$ and $\mathrm{ZnO}$ particles. The 100 structural and Lewis-acid properties of such species have been investigated in depth in several experimental and theoretical works.[109-121]

\subsubsection{Demetallation-metallation}

Since a major limitation of the atom-planting strategy is the 105 relatively low amount of metal incorporated into the solid, it was considered to start with a metallosilicate rather than a siliceous material and perform a treatment that would generate vacancies in 
a)
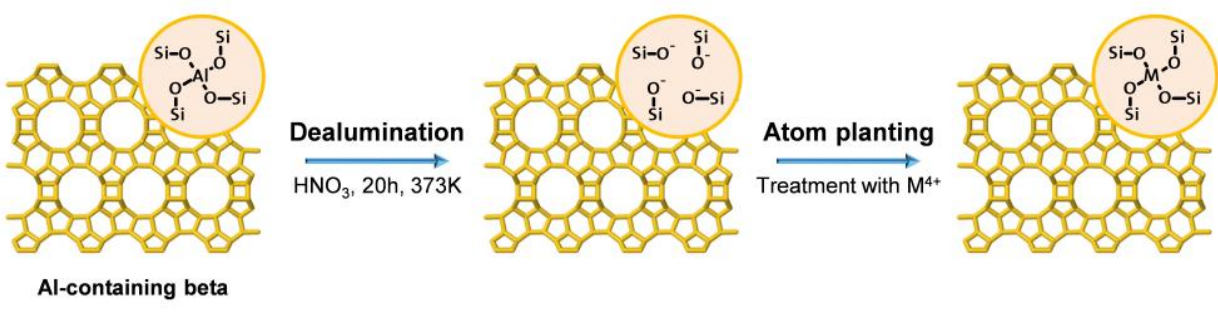

b)

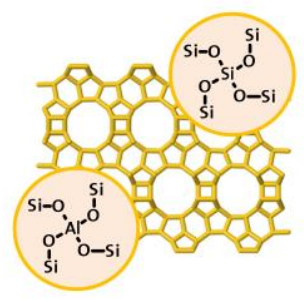

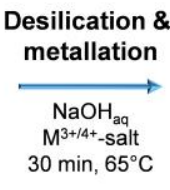

Any zeolite, any metal

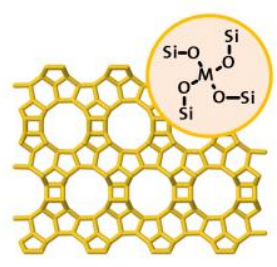

up to 8 wt. $\%$ Sn

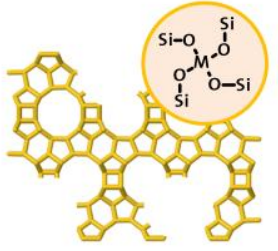

$\mathrm{S}_{\text {meso }}$ up to $300 \mathrm{~m}^{2} \mathrm{~g}^{-1}$

Fig. 6 (a) Two-step and (b) one-step post-synthetic approaches for the preparation of metal-containing zeolites.

the solid prior to metallation (Fig. 5a). The first work reporting this two-step approach is by Kraushaar and van Hooff [122] in 1988. Therein, the preparation of titanium-silicalite is accomplished by a triple acid treatment of a ZSM-5 zeolite with ${ }_{10} \mathrm{Si} / \mathrm{Al}=50$ in $1 \mathrm{M} \mathrm{HCl}$ at $353 \mathrm{~K}$ followed by gas-phase treatment of the obtained zeolite $(\mathrm{Si} / \mathrm{Al}=2000)$ with $\mathrm{TiCl}_{4}$. Though the amount of metal introduced was not reported, the incorporation of Ti in form of tetrahedral species was confirmed by XRD and by MAS NMR and FTIR spectroscopies. A similar post-synthetic 15 strategy was applied to MOR zeolites, i.e., dealumination by calcination at $973 \mathrm{~K}$ and treatment in $\mathrm{HNO}_{3}$ under reflux conditions followed by contact with a metal ( $\mathrm{Ti}, \mathrm{Ga}, \mathrm{Sb}$ ) halide vapour at 473-873 K.[123,124] The titanium-containing materials obtained featured tetrahedral $\mathrm{Ti}$ atoms fully incorporated into the 20 framework if the metallation was performed at high temperature, while a mixture of tetrahedral $\mathrm{Ti}$ species fully or partially integrated in the zeolite lattice upon a low-temperature metallation. The synthesis of titanium-containing beta zeolites was achieved by Rigutto et al. [125] either through demetallation 25 of boron-containing beta by mild treatment with diluted acid $(\mathrm{pH}$ $3,298 \mathrm{~K}, 24 \mathrm{~h}$ ) or methanol (vapour, $353 \mathrm{~K}, 16 \mathrm{~h}$ ) followed by reaction with $\mathrm{TiCl}_{4}$ vapours at $573 \mathrm{~K}$, or through the opposite sequence of steps, i.e., reaction of boron-beta with $\mathrm{TiCl}_{4}$ vapours, creating intermediate titanium species covalently bound but not

30 inserted into the framework and associated with a boron site, and subsequent deboronation enabling the complete framework incorporation of such 'framework satellites' Ti species. As supported by spectroscopic characterisation and catalytic evaluation in the $\mathrm{H}_{2} \mathrm{O}_{2}$-assisted epoxidation of 1-hexene, the 35 material prepared by metallation followed by deboronation via methanolysis appeared to contain the highest proportion of tetrahedral compared to non-tetrahedral Ti species. Lower boron contents in the starting zeolite also led to fewer non-tetrahedral Ti centres.

40 These demetallation-metallation approaches constitute the basis of the recent synthesis of Sn-containing zeolites mostly applied to the conversion of biobased substrates. Li et al. [126] reported that beta zeolites containing up to $6.2 \mathrm{wt} \% \mathrm{Sn}$ can be prepared by dealumination of a beta zeolite with $\mathrm{Si} / \mathrm{Al}=11$ via 45 treatment in a $6 \mathrm{M} \mathrm{HNO}_{3}$ solution $(353 \mathrm{~K}, 8 \mathrm{~h})$ followed by gasphase metallation with $\mathrm{SnCl}_{4}$ vapours at $673-773 \mathrm{~K}$. Spectroscopic investigations revealed that tin was mainly incorporated in form of tetrahedral species, but extraframework species were also produced, especially at high metal contents. ${ }_{50}$ Due to the higher metal loading and smaller crystal size, these solids exhibited superior catalytic properties in the selective oxidation of 2-adamantanone with $\mathrm{H}_{2} \mathrm{O}_{2}$ with respect to Sn-beta hydrothermally-synthesised in fluoride media. Liu et al. [127] applied a rather similar protocol to beta zeolites with $\mathrm{Si} / \mathrm{Al}$ or ${ }_{55} \mathrm{Si} / \mathrm{B}$ ratios of 15 , attaining materials with 3.3 and $6.0 \mathrm{wt} . \% \mathrm{Sn}$, respectively. In line with the previous study, both framework and extraframework Sn species were present in the zeolites, but the latter were more abundant in relation to the previous case. Based on the similar performance of these catalysts in the isomerisation 60 of glucose to fructose with respect to Sn-beta obtained by the bottom-up approach in fluoride media and pointing to literature work indicating that only framework species are catalytically active, the authors estimated the amount of lattice $\mathrm{Sn}$ sites in their samples to match that of the reference catalyst $(2.0 \mathrm{wt} \%)$. A 65 better utilisation of Sn was achieved by Jin et al.,[128] who, following an equivalent metallation protocol but targeting a lower Sn loading (1.2 wt.\%), introduced Sn virtually only at framework positions in dealuminated beta. Since the latter possessed intracrystalline mesoporosity (introduced upon its synthesis), the 70 catalysts featured enhanced accessibility to the active centres. Overall, these materials proved more active and selective than conventionally-prepared Sn-beta in the isomerisation of $\alpha$-pinene and glucose as well as in the oxidation of 2-adamantanone.

In addition to the studies reporting gas-phase metallation, other 75 works have explored the possibility to integrate the Lewis-acid metal by a solid- or liquid-phase reaction. Thus, Hammond et al. [42] ground a dealuminated beta zeolite with tin(II) acetate for $15 \mathrm{~min}$ and then calcined the mixture at $823 \mathrm{~K}$ under flowing air, obtaining a $10 \mathrm{wt} \%$ Sn-beta zeolite- with tin atoms occupying 
framework sites. Due to the high metal content, the catalyst attained superior space time yields than hydrothermallysynthesised Sn-beta in the Baeyer-Villiger oxidation of cyclohexanone and the isomerisation of DHA to ethyl lactate. ${ }_{5}$ Later work by the same group [36] demonstrated that this solidstate ion-exchange procedure can be extrapolated to $\mathrm{Zr}$, using $\mathrm{Zr}(\mathrm{IV})$ ethoxide as the metal source, but that ion implantation in the case of $\mathrm{Ti}$, using $\mathrm{Ti}(\mathrm{IV})$ ethoxide, can only occur by wet impregnation with an ethanolic solution of this salt. The catalysts 10 obtained comprised only a minor amount of extraframework Lewis-acid metal species and efficiently performed the isomerisation of glyceraldehyde into DHA and the epoxidation of cyclooctene. Tang et al. [129] prepared Ti-beta, containing 14 wt.\% of the Lewis-acid metal, through solid-state metallation 15 using titanocene dichloride as an alternative precursor. The authors evidenced by spectroscopic techniques that the organometallic $\mathrm{Ti}$ complex interacts with silanol nests and isolated defect $\mathrm{SiOH}$ groups generated upon dealumination of the starting beta zeolite leading to the replacement of the hydroxyl 20 protons by $\mathrm{Ti}$ species, which almost fully incorporated into the framework upon calcination. The epoxidation rate of 2cyclohexen-1-one was shown to linearly depend on the amount of lattice $\mathrm{Ti}$ atoms in these materials. Further research by the same group [130] broadened the application scope of organometallics 25 for the preparation of Lewis-acid zeolites, using zirconocene dichloride and dimethyl tin dichloride in the syntheses of $\mathrm{Zr}$ - and Sn-beta, respectively. Recently, they also showed that $\mathrm{Ti}, \mathrm{Sn}$ and $\mathrm{Zr}$ can be incorporated into mesoporous beta materials obtained by treatment with oxalic acid and sodium hydroxide, generating 30 efficient catalysts for the ring-opening of epoxides with amines.[131]

With respect to liquid-phase metallation approaches, Dijkmans et al. [54] introduced 0.03 to $0.72 \mathrm{mmol}$ of tin into dealuminated beta by refluxing the material into a isopropanolic solution 35 containing variable amount of $\mathrm{Sn}(\mathrm{IV})$ chloride pentahydrate for $7 \mathrm{~h}$. Materials with Sn loadings lower than $1 \mathrm{wt} . \%$ exclusively featured tetrahedral framework species, while those with higher metal contents were characterised by the copresence of $\mathrm{SnO}_{x}$ species. The former solids exhibited greater TOF per Sn site than 40 hydrothermally-prepared Sn-beta in the isomerisation of sugars, which was speculated to result from the high dispersion and good accessibility of tin. The same strategy applied to partially dealuminated beta samples led to materials exhibiting faster kinetics in DHA isomerisation to ethyl lactate due to the 45 beneficial impact of the residual Brønsted acidity onto the first and rate-determining step of the reaction, i.e., the dehydration of DHA to pyruvaldehyde.[43] Van der Graaf et al. [44] alternatively used impregnation with anhydrous $\mathrm{Sn}(\mathrm{IV})$ chloride to stannate dealuminated and dehydrated beta. Since they 50 removed the excess tin precursor by washing with methanol prior to calcination, their materials featured virtually no extraframework tin sites in spite of the substantial amount of metal loaded (up to 5.07 wt.\%) and displayed a similar productivity in DHA isomerisation in methanol to 55 hydrothermally-prepared Sn-beta. Guo et al. [39] focused on the MWW framework performing the metallation with Sn(IV) chloride pentahydrate under hydrothermal conditions and in the presence of hexamethyleneimine ( 3 days, $448 \mathrm{~K}$, under rotation) to ensure the recovery of crystalline materials. These solids ${ }_{60}$ displayed high performance for the conversion of sucrose, glucose and fructose to methyl lactate, although their turn-over number (TON) was inferior to hydrothermally-prepared Sn-beta. Wang et al. [132] synthesised Zr-beta through wet impregnation of dealuminated beta with $\mathrm{Zr}\left(\mathrm{NO}_{3}\right)_{4}$ affording a material showing 65 a better performance in the Meerwein-Ponndorf-Verley reduction of 1,4-cyclohexanedione, aromatic ketones and bulky adhehydes compared to Zr-beta obtained under hydrothermal conditions in the presence of fluoride ions in view of the higher metal content and the smaller crystal size.

70 Overall, demetallation-metallation comprises a more efficient and scalable method compared to the classical crystallisation in fluoride media to prepare highly active and selective Sncontaining beta zeolites. The strategy is also easier and environmentally more benign, especially if it relies on a solid or 75 liquid ion-exchange process with air-insensitive metal precursors rather than a gas-phase metallation. Still, two aspects should be highlighted. Firstly, although the approach is claimed to enable the insertion of higher amounts of tin, only at low loading it seems possible to ensure the full insertion of the metal into the 80 framework, implying that extraframework tin present is actually non-utilised. Nevertheless, it should be pointed out that while Sn was shown to insert at specific thermodynamically-favoured positions (T5/T6, vide infra) in the framework, demetallation could generate a broader variety of vacancies in the lattice, 85 effectively enabling the incorporation of a comparably higher amount of framework tin. Secondly, it seems apparent that the true advantage of this method is related to the fact that starting zeolites with small crystal size and/or inherent mesoporosity can be applied, which will endow the final materials with superior 90 mass transfer properties, i.e., accessibility of the metal sites.

Our group has recently introduced an alternative one-pot procedure to generate Lewis-acid zeolites, which uses desilication, via base leaching, rather than dealumination to promote the formation of the Lewis-acid centres. Alkaline 95 treatment of commercially-available zeolites has been widely studied in the last few years as a means to introduce mesoporosity and thus enhance molecular diffusion.[133] Interestingly, upon base leaching, changes in porosity have been accompanied by modifications in the acidic properties.[134] In particular, a direct 100 correlation was found between the development of external surface area and the Lewis acidity in ZSM-5 zeolites $(\mathrm{Si} / \mathrm{Al}=40)$ treated in alkaline solutions of progressively higher strength. These samples were active and selective for the isomerisation of DHA to lactic acid (Table 1).[41] Based on MAS NMR 105 spectroscopic investigations, it was concluded that the Lewis-acid centres created by alkaline treatment were mostly tetracoordinated. In view of the propensity of aluminium to redistribute upon base leaching, it was attempted to introduce $\mathrm{Al}$ centres in silicalite-1 upon alkaline treatment.[41] Thus, a soluble 110 aluminium salt $\left(\mathrm{Al}\left(\mathrm{NO}_{3}\right)_{3}\right)$ was added to the $\mathrm{NaOH}$ solution used for the modification (Fig. 6b). The obtained catalysts displayed similar performance to those produced by simple alkaline treatment. The scope of this so-called 'alkaline-assisted metallation' was broadened applying other metals that can give 115 rise to Lewis acidity. At first, gallium was introduced into the FAU framework leading to highly performing catalysts for the 
isomerisation of DHA to ethyl lactate.[32,46] Characterisation by MAS NMR spectroscopy revealed that the majority of gallium atoms incorporated have a tetrahedral geometry. It is worth noting that the use of trivalent atoms will unavoidably lead to 5 species located at framework positions, thus giving rise to Brønsted acidity. While the latter might be beneficial to catalyse cascade reactions[35] or promote DHA isomerisation, it leads to the formation of undesired by-products in the isomerisation of hexoses, pentose and other trioses.[45] Therefore, the 10 introduction of tetravalent atoms such as Sn that will exclusively give rise to Lewis acidity upon incorporation was attempted using silicalite-1 as the starting material.[32,51] The stannated zeolite material demonstrated extremely active and selective in the continuous isomerisation of glyoxal to glycolic acid. Its 15 performance was only slightly inferior compared to hydrothermally-synthesised Sn-MFI. DR-UV/Vis spectroscopy pointed to a moderately broader distribution of the environment of the tin atoms as the reason for this discrepancy.[32] Interestingly, XPS analysis evidenced that most of the tin centres 20 are inserted at the surface of the crystals. Accordingly, stannated MFI zeolites could also enable the isomerisation of access- and diffusion-limited sugars with good yields.[51]

This one-step post-synthetic method to produce Lewis-acid zeolites appears to hold bright perspectives with respect to a 25 future industrial application. Indeed, base leaching of ZSM-5 has already been demonstrated at the pilot scale.[135] Additionally, whereas the application of other demetallation-metallation approaches is restricted to zeolites that can be easily dealuminated (i.e., BEA), this strategy can be followed starting 30 with Al-rich or Al-lean zeolites featuring any type of framework. Furthermore, it has the benefit of preferentially incorporating the metal at the most accessible location of the crystal and to generate mesoporosity in a single treatment.

\subsubsection{Steaming}

35 This post-synthetic method has not been applied as such to generate Lewis-acid zeolites. Nevertheless, studies by West et al. [40], Pescarmona et al. [45] and Paniagua et al.[53] have identified zeolites rich in extraframework $\mathrm{Al}$ species (e.g., $\mathrm{H}$ USY with $\mathrm{Si} / \mathrm{Al}=2.6$ or 6 , whose industrial preparation includes 40 such step) as rather efficient catalysts for the isomerisation of DHA and xylose. In particular, the second work has highlighted an inverse relation between the fraction of $\mathrm{Al}$ in the framework and the yield of methyl lactate. The fact that $\mathrm{Al}$ species formed upon steaming of ZSM-5 ( $\mathrm{Si} / \mathrm{Al}=15$ and 40$)$ can act as Lewis45 acid centres displaying moderately high isomerisation efficiency has also been confirmed by us.[41] The intrinsic drawback of steaming seems related to the little control over the speciation of the extraframework Al species that are generated (mixture of distorted tetrahedral, pentahedral and octahedral species).[41]

\section{${ }_{50}$ 3. Characterisation of Lewis-acid centres}

In order to derive property-performance relationships and thus ultimately design optimal catalysts, the determination of the electronic, structural and acidic properties of the Lewis-acid metals introduced into the zeolites is crucial. This section aims at

55 summarising the main techniques used to shed light onto these features including those commonly applied to aluminosilicate

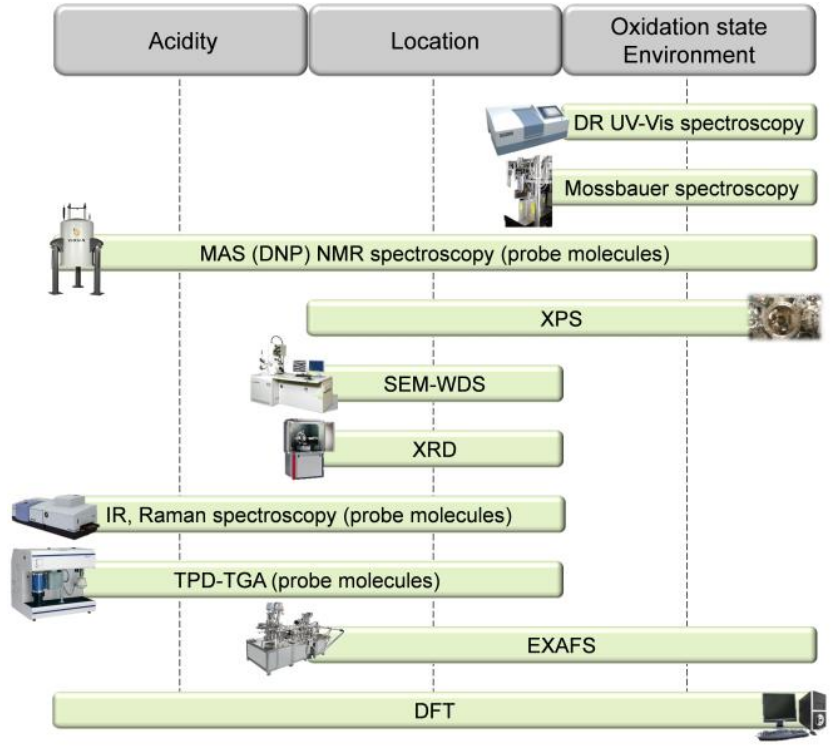

Fig. 7 Main techniques used for the characterisation of Lewis-acid centres and type of information gained.

zeolites as well as the ones more specifically developed for 60 transition metal-containing zeolites (Fig. 7). Since characterisation results of solids prepared following distinct routes often are very similar but the materials display different catalytic activity, particular emphasis is devoted to evaluate the reliability of the information that is obtained. This critical 65 overview of experimental methods is complemented by a brief description of the insights gained by modelling by Density Functional Theory in terms of site definition as well as of molecular-level understanding of reaction mechanisms.

\subsection{Oxidation state and environment}

$70 \quad D R-U V / V i s$ spectroscopy. This technique is one of the most widely used methods to quickly assess the environment of the metal Lewis-acid centre in the zeolite. Although convenient, due to its high sensitivity to the preparation method, different spectra are often displayed in literature for similar materials, easily 75 generating misunderstanding. In order to ensure reproducibility, samples must be degassed well [136] and diluted homogeneously (1-5 wt.\%) with a non-absorbing matrix (e.g., $\mathrm{BaSO}_{4}$ or the corresponding pure-silica zeolite) to minimise the specular reflections causing changes in band shapes and their relative 80 intensity. Furthermore, since the reflective surface of the DR chamber absorbs electromagnetic radiation above $220 \mathrm{~nm}$, it should be ensured that the instrument can quantitatively operate in this spectral region. DR-UV/Vis spectroscopy has been applied for the first time by Klaas et al. [137] in order to discriminate and 85 quantify intra- and extraframework metal species through the conversion of the reflectance to the Kubelka-Munk function, which enables to linearly correlate intensity and concentration. Generally, an absorption band around $200-210 \mathrm{~nm}$, corresponding to a charge transfer from $\mathrm{O}^{2-}$ to $\mathrm{M}^{4+}$, has been undoubtedly 90 associated with a framework metal.[138] Whereas this band is generally well-centred and narrow for Sn-MFI,[139] that of SnBEA is typically less defined and wider. The origin of the contribution appearing at lower energy $(240$ and $280 \mathrm{~nm})$ is still not fully clear and might be due to the formation of 
pentacoordinated species upon water adsorption.[140] Still, the most probable explanation is the presence of $\mathrm{SnO}_{x}$ clusters which possess a larger size compared to isolated tin sites. Although hydrothermally-synthesised Sn-BEA is often claimed as tin 5 oxide-free, oxidic species are unavoidably present at the surface of the crystals especially when the $\mathrm{Si} / \mathrm{Sn}$ ratio approaches 150.[79]

Mössbauer spectroscopy. This technique, not frequently applied, relies on the resonance phenomena occurring upon 10 absorption by the metal-containing zeolite of recoilless $\gamma$-rays emitted by a radioactive source (consisting of an isotope of the metal to be probed) upon $\gamma$-decay. Consequently, Mössbauer spectroscopy possesses the highest resolution among all of the spectroscopic techniques. While a single absorption line at 15 velocity of $0 \mathrm{~mm} \mathrm{~s}^{-1}$ is observed when the emitting and absorbing source share exactly the same environment, the wide range of environments encountered in metal-containing zeolites modify the energy levels (by means of isomer shift, quadrupole and magnetic splitting) leading to change in peak shape and 20 displacement of velocity. This ultimately enables to gain information regarding oxidation states and local environments. This technique can be specifically applied to elements having a suitable isotope (short half-life time and small energy $\gamma$-rays) such as Ga and, in particular, Sn.[141] Upon reduction and 25 subsequent oxidation of Sn-MFI, Sn(IV), Sn(II) and $\mathrm{Sn}(0)$ could be clearly distinguished,[142] while hydrothermally-synthesised Sn-MFI only contained tetravalent $\mathrm{Sn}$ centres. While precisely discriminating between oxidation states, this method is blind with respect to the structure of the metal centres, e.g., $\mathrm{Sn}(\mathrm{IV})$ atoms in 30 framework position produce the same signal as $\mathrm{Sn}$ (IV) atoms in $\mathrm{SnO}_{2} \cdot[143]$

(DNP) MAS NMR spectroscopy. Solid-state NMR spectroscopy is one of the most powerful tools in order to gather information regarding the structure of the metal centres. While ${ }^{35}{ }^{71} \mathrm{Ga}$ MAS NMR spectroscopic studies are rather straightforward and have enabled us to demonstrate the tetra-coordinated nature of Lewis-acid Ga centres introduced in USY zeolites upon alkaline-assisted metallation,[46] the analysis of transition metalcontaining zeolites, i.e., Sn, has proved more challenging. Indeed, ${ }_{40}$ due to the low natural abundance of ${ }^{119} \mathrm{Sn}(\mathrm{ca} .8 .6 \%)$, its intrinsically low NMR activity as well as the low metal loading in the samples, the use of materials prepared with a ${ }^{119} \mathrm{Sn}$-enriched source is required in order to acquire spectra with sufficiently high signal to noise ratio.[78] Only following this strategy, the 45 structure of the Sn centres in hydrothermally-synthesised Sn-MFI and Sn-BEA has been successfully determined. In particular, closed tetrahedral $(\mathrm{Td})$ tin sites $(\mathrm{Sn}(\mathrm{OSi}) 4)$ have been uncovered in Sn-MFI,[29] whereas Td tin centres in both closed and open $\left(\mathrm{OH}-\mathrm{Sn}(\mathrm{OSi})_{3}\right)$ configurations have been identified in $\mathrm{Sn}$ ${ }_{50} \mathrm{BEA}$.[78] In the latter, one bond with a $\mathrm{Si}$ atom through a bridging $\mathrm{O}$ atom has been hydrolysed resulting in $\mathrm{Sn}-\mathrm{OH}$ and concomitantly leaving a proximal silanol group. Interestingly, since $\mathrm{SnO}_{x}$ produces signals at a different chemical shift (-605 ppm), its presence can be easily identified.[78] Still, since ${ }_{55} \mathrm{Td} \mathrm{Sn}$ atoms easily extend their coordination sphere from 4 to 6 upon addition of two molecules of water, shifting the peak position from -400 to $-650 \mathrm{ppm}$, samples have to be dehydrated for a meaningful analysis.[139] Aiming at avoiding demanding

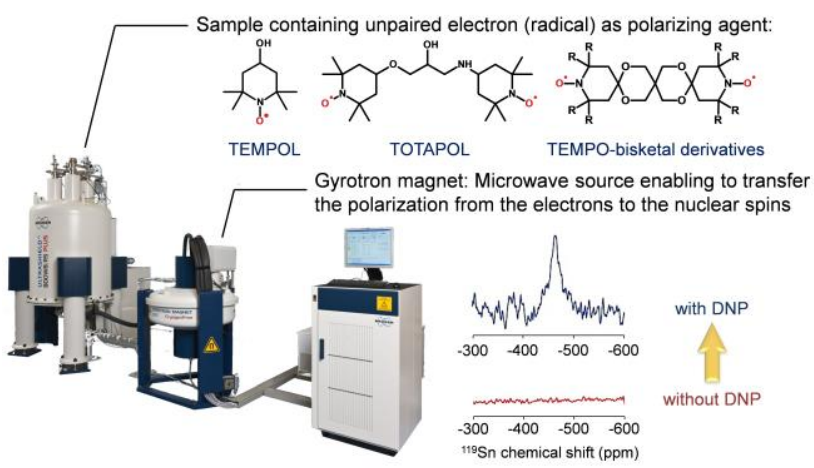

Fig. 8 Instrumentation required for DNP MAS NMR spectroscopy 60 measurements and exemplification of the gain in sensitivity achieved with this technique compared to conventional MAS NMR spectroscopy. Image used with the permission of Bruker.

preparations with ${ }^{119} \mathrm{Sn}$-enriched tin precursors and long acquisition times, it has been recently investigated whether high65 quality spectra could be rapidly acquired with standard materials through the application of the dynamic nuclear polarisation (DNP) method to MAS NMR spectroscopy.[143,144] The equipment and chemical additives required by DNP MAS NMR measurements are displayed in Fig. 8. During the analysis, 70 transfer of polarisation occurs from an exogenous biradical to the sample through the assistance of a glassing agent mixed with it. This method proved effective in reducing the acquisition times from 10 to 1 day. While the group of Román-Leshkov investigated hydrothermally-synthesised Sn-BEA, Wolf et al. 75 applied the technique to Sn-BEA samples containing various amount of Sn ( 0.5 to $10 \mathrm{wt} . \%)$ and prepared by demetallation followed by solid-state metallation. The latter materials were shown to contain a significant amount of Td tin centres with a ratio between open and closed sites depending on the loading.

80 Interestingly, the presence of tin oxide was also detected in all of the samples, whereas no trace of it was shown using Mössbauer spectroscopy. Noteworthy, the DNP method only allows to shorten the acquisition time but not to increase the resolution of the spectra.

$85 X P S$. This technique provides information on the metal oxidation state as well as its proximal environment. Since the spectra are typically shifted according to (arbitrarily selected) standards, binding energy values reported in the literature for similar materials might differ and the direct comparison of 90 samples displaying different structure (e.g., framework Sn vs. bulk $\mathrm{SnO}_{2}$ ) should be carefully made. In particular, the technique does not specifically discriminate the presence of $\mathrm{SnO}_{x}$ clusters.

\subsection{Location}

SEM. This microscopic technique gives direct information 95 regarding crystal size and morphology. If coupled with wavelength-dispersive spectroscopy (WDS), it also enables the acquisition of elemental X-ray compositional maps. SEM has been used by Tolborg et al. [79] in order to follow the evolution of the tin concentration in hydrothermally-synthesised Sn-BEA 100 crystals obtained at variable crystallisation stages from gels with distinct $\mathrm{Si} / \mathrm{Sn}$ ratio (vide supra).

(Synchrotron) XRD. This method has proved suitable to confirm the incorporation of metals into the zeolite framework. Indeed, the isomorphous substitution of $\mathrm{Si}$ by a larger metal 
induces an increase of the unit cell volume, thus giving rise to a shift of the associated diffractions peaks. In particular, a linear relationship was demonstrated between the increase of the $a, b$ and c cell parameters as well as its volume with the amount of Ti 5 incorporated in silicalite-1.[24] The technique was lately applied by Mal et al. [29] to confirm the successful integration of Sn into the MFI framework. Remarkably, Millini et al.,[145] based on the linear correlation and using Rietveld-refined XRD patterns, estimated the maximum amount of Ti that can be introduced into 10 the MFI framework upon hydrothermal synthesis. This corresponded to a $\mathrm{Si} / \mathrm{Ti}$ ratio of 40 . This finding is in line with the DR-UV/Vis spectroscopic analysis carried out on Sn-MFI revealing the presence of extraframework metal in samples with decreasing M/Si ratio.[139] Upon using synchrotron radiation, ${ }_{15} \mathrm{XRD}$ might also enable the identification preferential crystallographic site (T-site) substitutions.[146]

FTIR and Raman spectroscopies. It has been believed for a long time that the presence of a band at $960 \mathrm{~cm}^{-1}$ in FTIR spectra was indicative of Si-O-M bonds since its intensity was shown to 20 progressively increase with the metal content.[136,147] Nevertheless, a similar absorption band was also observed for some metal-free silicalite-1 samples,[148] thus questioning its origin. In order to solve this issue, Li et al. [149] carried out UV Raman spectroscopy on silicalite-1 and TS-1 samples excited 25 using a laser line $(244 \mathrm{~nm})$ corresponding to the charge transfer transition of framework titanium species. Based on these experiments, the authors hypothesised that the band at $960 \mathrm{~cm}^{-1}$ was associated to $\mathrm{Si}-\mathrm{O}-\mathrm{Si}$ linkages next to $\mathrm{M}-\mathrm{O}-\mathrm{Si}$ bonds and identified contributions attributed to transition-metal ions bonded 30 to the framework at 490,530 and $1127 \mathrm{~cm}^{-1}$ in the UV Raman spectra. Recently, Courtney et al. [150] demonstrated that the band at $960 \mathrm{~cm}^{-1}$ actually originates from the presence of isolated internal silanol groups formed upon hydroxylation of defects and which appear more abundant in beta zeolites with high Sn 35 contents.

EXAFS. This method has been shown as a valuable tool in order to determine the exact location, in terms of T-site, of the active centres in zeolites, which in turn determines their geometry and, ultimately, their reactivity. In spite of extensive 40 investigations, EXAFS studies on TS-1 were not able to clearly identify a preferential location of $\mathrm{Ti}$ in the MFI framework.[151,152,153] In contrast, Bare et al. [154] demonstrated that $\mathrm{Sn}$ is not randomly incorporated in the BEA framework upon hydrothermal synthesis but inserts at specific 45 positions, that is T5 and T6 sites in the six-membered ring. Furthermore, the data showed that $\mathrm{Sn}$ atoms distribute in pairs on opposite sides of the six-membered-ring. This preferential $\mathrm{Sn}$ location in Sn-BEA is extremely interesting and could explain why hydrothermally-prepared samples displayed higher TOF than 50 samples prepared by post-synthetic approaches for the same Sn content. Indeed, it is likely that $\mathrm{Sn}$ incorporates into the dealuminated BEA framework randomly, thus having suboptimal geometry.

$X P S$. In addition to the information on electronic properties, 55 the surface sensitivity of this technique combined with sputtering methods allows establishing metal concentration depth profiles. For instance, our group has recently demonstrated that alkalineassisted metallation leads to samples possessing a strongly tin- enriched outer surface compared to hydrothermally-prepared Sn60 MFI.[51]

\subsection{Acidity}

FTIR spectroscopy. Besides for assessing metal incorporation, FTIR spectroscopy of adsorbed basic probe molecules is also extremely relevant in order to evaluate the concentration and 65 strength of Lewis-acid centres. Pyridine has been most commonly applied for this purpose but also $\mathrm{d}_{3}$-acetonitrile and cyclohexanone have been used. The former enables the determination of the Lewis-acid sites concentration, while the Lewis-acid strength is generally derived from the chemical shift 70 of the carbonyl and nitrile stretching vibrations of cyclohexanone and $\mathrm{d}_{3}$-acetontrile, respectively, upon adsorption on the metal.[78,18] In this context, Osmundsen et al. [18] have demonstrated that substituting $\mathrm{Si}$ by $\mathrm{Ti}, \mathrm{Zr}$ and $\mathrm{Sn}$ in the BEA framework led, upon $\mathrm{d}_{3}$-acetontrile adsorption, to a progressive 75 shift of the absorption band that correlates to the strength of the Lewis-acid sites and in turn to the catalytic activity of the three materials. Interestingly, since no shift is observed upon $\mathrm{d}_{3}$ acetonitrile adsorption on metal oxides, only framework metal atoms contribute to the chemical shift.[155] This could be 80 advantageously used to quantitatively determine metal incorporation efficiency of the various post-synthetic approaches described above.

TPD-TGA. This technique, not commonly applied to study Lewis-acid zeolites, has proved extremely useful to determine the 85 stoichiometry of adsorption complexes on metal sites.[156] While adsorption of $\mathrm{NH}_{3}$ is usually practiced but lacks of reliability, the use of weaker basic probe molecules which can undergo reaction/decomposition at moderate temperatures $(400-700 \mathrm{~K})$ appears more suited to gather information regarding the nature of 90 the acid sites as well as their respective amount.[157]. In this context, Roy et al. [158] have recently used acetonitrile, diethyl ether and 2-methyl-2-propanol to investigate the Lewis-acid sites in Sn-BEA. By comparing the amount of probe molecules (pure and in combination with water) adsorbed on Sn-BEA, Si-BEA 95 and $\mathrm{Si}-\mathrm{BEA} / \mathrm{SnO}_{x}$ as well as the product decomposition profiles, the authors were able to conclude that extraframework Sn centres can also act as Lewis-acid sites, although being less active. They also found that the adsorption of acetonitrile is hindered in the presence of water, which implies that molecules bearing such 100 functional groups cannot be converted in aqueous media.

MAS NMR spectroscopy. Similarly to study of Brønsted-acid sites in zeolites by ${ }^{31} \mathrm{P}$ MAS NMR spectroscopic studies of adsorbed trimethylphosphine oxide and tributylphosphine oxide, $[159,160]$ NMR-active probe molecules which adsorb on 105 Lewis-acid sites could be attractively used to gather information regarding the Lewis-acid strength. In this respect, trialkylphosphines successfully distinguished Lewis-acid sites of different strength in commercial USY zeolites.[160,161] Indeed, the broad range $(430 \mathrm{ppm})$ of chemical shift of ${ }^{31} \mathrm{P}$ allows 110 appreciating small variations of acidity. It would be worth uncovering whether this strategy can be extrapolated to study transition-metal containing zeolites. If probe molecules of different size were employed, additional information regarding the location of the metal centres could be attained.[162] 


\subsection{Molecular modelling}

Molecular modelling by Density Functional Theory simulations has revealed a precious tool to shed light onto the structural, acidic and hydrophilic properties of Lewis-acid centres in zeolites 5 as well as to gain insight into the mechanism of glucose iso/epimerisation and glyceraldehyde isomerisation over these sites. Concerning the first aspect, Shetty et al. [163] have shown that $\mathrm{Sn}$ and $\mathrm{Ti}$ atoms may occupy $\mathrm{T} 2$ and/or T1 crystallographic positions in BEA and that the first coordination shell of $\mathrm{Sn}$ is 10 larger than that of $\mathrm{Ti}$, but the second shell is similar. In addition, they have found that incorporation of $\mathrm{Ti}$ is more favorable than that of $\mathrm{Sn}$, but the latter features a stronger Lewis acidity, supporting the superiority of tin-containing zeolites in catalytic applications, and is more hydrophilic. Theoretical investigations 15 by Yang et al. [164] corroborated the placement of $\mathrm{Ti}, \mathrm{Sn}$ or $\mathrm{Zr}$ at T2 sites and explained the better Lewis-acidic properties of SnBEA compared to Ti-BEA and Zr-BEA by the presence of paired lattice sites, which are stable even at distances below $5 \AA$.

With respect to molecular undestanding of glucose conversion, 20 the group of Davis [57] first revealed the rate-determining step of its isomerisation, the hydride shift, and the nature of the active site in Sn-BEA, an open tin centre with an adjacent silanol (see section 4.1). Later studies by Yang et al. [165] indicated that a perfect lattice tin site and hydroxylated $\mathrm{SnOH}$ species have 25 similar reactivity and that that of the latter can be enhanced by the presence of an extended silanol nest in the vicinity which activates the substrate. This result was substantiated by the group of Bell,[166] who also pointed out that $\mathrm{Sn}$ and $\mathrm{Zr}$ result in the lowest reaction barrier compared to $\mathrm{Ti}, \mathrm{Si}, \mathrm{V}, \mathrm{Nb}$ and $\mathrm{Ge}$ due to a 30 stronger Brønsted basicity of the oxygen atom bound to the metal and a more favorable polarisation of the metal atom, respectively. Rai et al. [167] confirmed the crucial role of the proximal silanol group in glucose isomerisation but found that it has no impact in its epimerisation. Analysis of glucose isomerisation on tin35 containing MOR, MFI and MWW zeolites by Li et al. [168] generalised the essential role of the proximal hydroxyl group, which could derived from co-adsorbed water molecules or internal silanols, and especially facilitates the hydride shift over Sn-MWW in view of a higher acidity. Similarly to the case of 40 glucose, the reactivity sequence of Lewis-acid metals in beta zeolites for glyceraldehyde isomerisation is $\mathrm{Sn}>\mathrm{Zr}>\mathrm{Ti}$, the ratedetermining step is the hydride shift and an active participation of the hydroxyl group coordinated to the metal site is required.[169] With respect to glucose epimerisation, the group of Mushrif [170] 45 investigated the synergetic effect of borate salts and Sn-BEA responsible for the preferential formation of mannose. They demonstrated that the energetically most favorable conformation of the borate-glucose complex inhibits the 1,2-H shift, thus indirectly promoting the more demanding $1,2-\mathrm{C}$ shift.

50 Based on these findings, since the higher surface defectivity observed for materials obtained by top-down methods might be a beneficial characteristic to enhance the reactivity, but these solids exhibit lower TOF compared to hydrothermally-prepared SnBEA for equivalent tin loading, it is supposed that the placement 55 of tin centres might ultimately have a higher impact on the activity.

\section{Process design from lab towards large scale}

\subsection{Steering selectivity by varying the nature of the metal and 60 its environment}

In 2010, the group of Davis [55] reported hydrothermallysynthesised Sn-beta as an outstandingly active and selective catalyst for the isomerisation of glucose to fructose in aqueous media. In this work, the authors suggest that the active sites ${ }_{65}$ comprise $\mathrm{Sn}$ atoms in lattice positions of the zeolite which mediate the formal transfer of a hydrogen atom from the $\mathrm{C} 2$ to $\mathrm{C} 1$ positions of the $\alpha$-hydroxy aldehyde substrate. This is achieved through coordination by the metal of the oxygen atoms of the carbonyl and adjacent hydroxyl groups of the sugar. The validity 70 of the intramolecular hydride shift mechanism of glucose isomerisation was experimentally confirmed by Román-Leshkov et al.,[56] but later work [57] revealed that the active tin sites actually are open rather than close. DFT calculations indicated that the latter interacts with a hydroxyl group of glucose upon its 75 adsorption on the tin site. Interestingly, upon conversion of glucose over Sn-beta in methanol, epimerisation to mannose through intramolecular carbon shift was shown to fully prevail over isomerisation to fructose (Fig. 9a).[63] This change in activity and selectivity upon replacement of the medium was 80 shown to be specific to the tin centres but remains unexplained at a molecular level. Suppression of the isomerisation pathway could also be obtained in either water or methanol by using Nacontaining Sn-beta obtained by post-synthetic ion exchange or by $\mathrm{NaNO}_{3}$ addition to the synthesis gel,[64] in which the silanol in 85 proximity to the $\mathrm{Sn}$ site is transformed into a Si-ONa centre (Fig. 8a). Since the material is decationated upon operation in water, addition of $\mathrm{NaCl}$ to the reaction mixture is required to avoid a progressive alteration of the selectivity in favour to the isomerisation product.

90 Alterations in the product selectivity patterns of glucose conversion were also demonstrated on beta zeolites substituted with Ti instead of Sn (Fig. 9a).[66] Glucose was predominantly transformed into fructose in water, in analogy to the Sn-beta case, but into sorbose through a C5-C1 hydride shift in methanol.

95 Recently, Tolborg et al. [69] have shown that alkali ions added to the synthesis gel in the hydrothermal synthesis of Snbeta, to Sn-beta obtained via the method by Hammond et al. [42] through impregnation, or directly to the reaction mixture improve the selectivity of the conversion of sucrose to methyl lactate in 100 methanol. The authors suggest that this might be the result of the neutralisation of Brønsted acidity from defects in the framework which catalyse side reactions.

\subsection{Enhancing activity by tuning the metal content}

It has been claimed that one main advantage of the post105 synthetic approach comprising dealumination followed by metallation compared to the hydrothermal route for preparing SnBEA is the possibility to easily incorporate a significant amount of metal in the zeolite (e.g., $10 \mathrm{wt} . \%)$, thus enhancing the productivity of the catalyst.[42] In order to unravel the influence 110 of the tin content on the catalyst performance, Dijkmans et al. [54] prepared samples containing 0.3-8.6wt.\% Sn by demetallation followed by liquid-phase stannation and evaluated them in the isomerisation of glucose to fructose (Fig. 9b). Interestingly, they observed enhanced performance for the 
a)

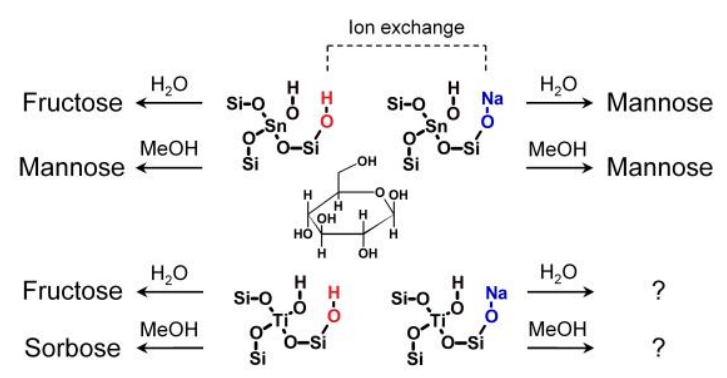

c)

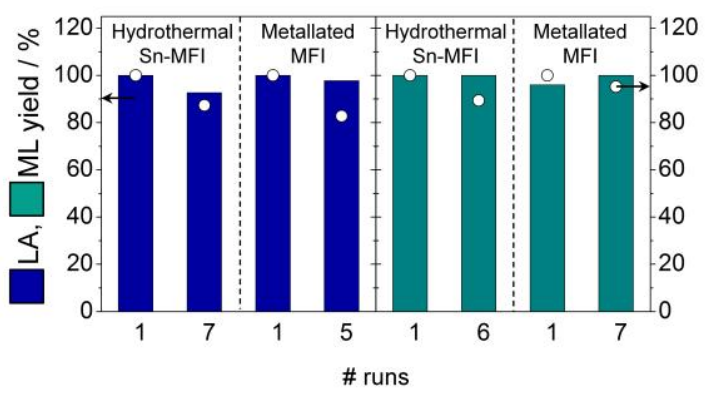

b)
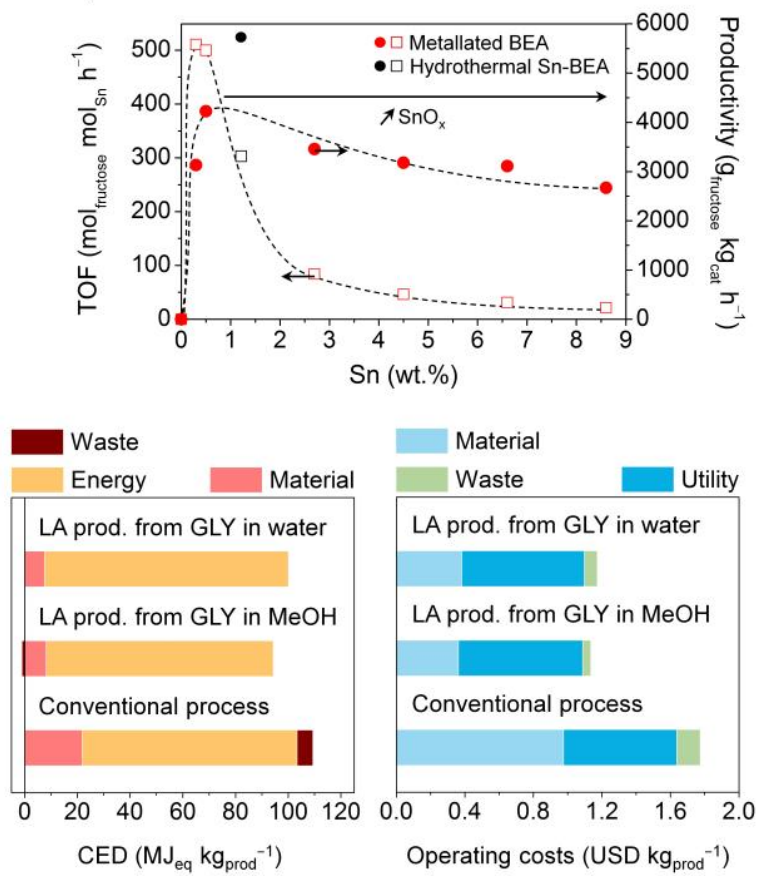

Fig. 9 (a) Dependence of the selectivity pattern for glucose conversion on the nature of the Lewis-acid metal and the presence of proximal $\mathrm{H}$ and Na atoms. (b) Dependence of the TOF and productivity on the amount of tin centres in the isomerisation of glucose to fructose. (c) Dependence of the 5 performance in the conversion of substrates of increasing size on the type of zeolite framework.

catalysts featuring a lower metal content, as later confirmed by Wolf et al. for zeolites obtained by solid-state metallation of dealuminated beta applied to the same reaction.[36] In particular, a TOF of $500 \mathrm{~h}^{-1}$ and a productivity of $4224 \mathrm{~g}_{\text {fructose }} \mathrm{kg}_{\mathrm{cat}}{ }^{-1} \mathrm{~h}^{-1}$ 10 were determined for the sample containing only $0.5 \mathrm{wt} \% \mathrm{Sn}$. These values are higher and lower, respectively, compared to those $\left(305 \mathrm{~h}^{-1}\right.$ and $\left.5880 \mathrm{~g}_{\text {fructose }} \mathrm{kg}_{\mathrm{cat}}{ }^{-1} \mathrm{~h}^{-1}\right)$ obtained for the hydrothermally-synthesised Sn-BEA (1.3 wt.\% Sn) reference catalyst. The authors hypothesised that the higher TOF of their 15 material likely originated from a higher concentration of partially hydrolysed tin sites as well as from a higher metal dispersion. Nevertheless, based on the higher productivity of the tin-richer Sn-BEA sample prepared under hydrothermal conditions and as suggested by the study by Tolborg et al.,[79] it is expected that 20 zeolites prepared by the bottom-up approach and containing less tin will reach TOF values significantly higher than $500 \mathrm{~h}^{-1}$. Since state-of-the-art characterisation techniques did not highlight any significant difference among the solids, the distinct hydrophobicity and/or the framework location of the tin species

25 might be the actual critical parameters. While Sn tends to occupy the more thermodynamically favoured T5/T6 sites in the hydrothermally-prepared sample,[154] it might be integrated at different positions upon use of post-synthetic methodologies, ultimately leading to Sn centres with less appropriate geometry.

\section{${ }_{30}$ 4.3. Identifying critical factors for industrial viability}

So far, research efforts have mainly focused on the development of Lewis-acid catalysts displaying high productivity and selectivity in targeted applications, while an evaluation of the industrial viability of the processes introduced by life cycle and
35 economic analysis has been hardly performed. Clearly, the use of biobased substrates does not necessarily imply that the production of a chemical will be greener and more profitable than that based on a fossil-based route. In this respect, ecological and economic metrics can be instrumental in shedding light onto critical 40 parameters for a large-scale implementation of a system, thus guiding research at the lab-scale level. Our group [33] has recently demonstrated that a cascade process comprising the enzymatic production of dihydroxyacetone from crude glycerol and its Lewis-acid catalysed isomerisation over tin-containing ${ }_{45}$ MFI zeolites prepared by either hydrothermal synthesis or alkaline-assisted metallation is more sustainable and less costly for the production of lactic acid compared to the currentlypracticed glucose fermentation. While the economic advantage is strongly determined by the comparably low market price of 50 glycerol, the reduced energy requirements and $\mathrm{CO}_{2}$ emissions originate from the valorisation of a waste feedstock and the high performance and recyclability of the zeolite catalyst (Fig. 9c). The use of methanol rather than water for the isomerisation step enables further energy saving. In fact, the downstream separation 55 and purification procedures are energetically and economically less intensive although one additional step, i.e., the hydrolysis of the methyl lactate formed, is required. It is worth noting that although the activity and selectivity of the zeolites was retained in either solvent upon reuse in subsequent cycles (Fig. 9c), tin ${ }_{60}$ leaching was detected, being more pronounced in water. Based on the recent work of Guo et al. [39] showing the deactivation of Sn-BEA in the isomerisation of DHA in water and on the proved stability of the same catalyst in a $0.1 \mathrm{M} \mathrm{HCl}$ solution,[55] the impact of the rather low $\mathrm{pH}$ of the reaction mixture upon 
formation of lactic acid on the metal loss seems negligible. It is put forward that the latter is mostly aided by the ligand properties of the product, especially in its free-acid form.

\section{Conclusion and outlook}

${ }_{5}$ Owing to their oxygenated nature, biobased feedstocks can be valorised by means of simple transformations such as isomerisation, retroaldol and $\mathrm{H}$-transfer reactions attaining commodity and high-volume intermediate chemicals. Lewis-acid materials play a pivotal role in these conversions. Among porous 10 solids, metal-containing high-silica zeolites have demonstrated more promising catalysts compared to other Lewis-acid materials owing to their crystallinity and higher hydrophobicity. These features majorly enable the retention of their Lewis-acid character in aqueous media. Nevertheless, the industrial implementation of 15 catalytic systems displaying encouraging results at the laboratory scale will strongly be impacted by the scalability of the methods applied for their preparation. Herein, bottom-up and top-down approaches have been reviewed and discussed in terms of industrial amenability as well as, more fundamentally, of site 20 speciation and versatility. Hydrothermally-prepared samples (e.g., Sn-MFI, Sn-BEA) generally displayed the highest activity and selectivity owing to the well-defined nature and placement of their Lewis-acid sites. While there seems to be no big hurdle for the large-scale production of the small-pore Sn-MFI, the need for ${ }_{25} \mathrm{HF}$ in the preparation of the large-pore $\mathrm{Sn}-\mathrm{BEA}$ is perceived as a killing factor for this exceptional catalytic material. Therefore, the more industrially-amenable post-synthetic demetallationmetallation strategies introduced to prepare large-pore metalcontaining zeolites stand as an appealing alternative.

30 On the characterisation side, particular emphasis has been placed on the need to combine methods to discriminate between the geometry and the location of the active sites as well as their proximal environments. In this respect, DNP MAS NMR spectroscopy and theoretical calculations have appeared as 35 excellent complementary tools to further understand the nature of the Lewis sites. As hinted by the studies selected to exemplify attempts to relate synthesis, properties and performance, future research in the field should provide an improved understanding of the role of surface features on the catalytic performance, i.e., 40 decoupling it from the impact of the mass transfer properties induced by the crystal size in the case of hydrothermally-prepared materials. For this purpose, the particle size of Sn-BEA or SnMFI prepared in fluoride media could be modulated by the addition of seeds to match that of the materials obtained by the 45 hydroxide route. In addition, the location (i.e., T-site occupied) of the metal centres should be unveiled also for zeolites prepared by post-synthesis methods. This might be achieved combining EXAFS, XANES and adsorption studies and would be instrumental to guide the post-synthetic design of materials 50 whose catalytic behaviour matches or hopefully even exceeds that of hydrothermally-prepared samples. Furthermore, one issue that should be prioritised comprises a rigorous analysis of stability of these catalysts in liquid media. In fact, while the preparation method does not seem to significantly affect the selectivity of the 55 zeolite and the mass of the catalyst in the reactor could be adjusted to compensate for an inferior activity, stability will ultimately be the decisive for a prospective industrial implementation. In this respect, not only the robustness of individual samples is infrequently assessed but comparative 60 studies aiming at correlating preparation methods and lifetime are hardly pursued. Furthermore, the relative impact of temperature, solvent polarity, substrate properties, and framework topology on deactivation phenomena are not clear. So far, it has been envisaged that the defect-free nature of hydrothermally-prepared ${ }_{65} \mathrm{Sn}$-BEA compared to Sn-MFI crystallised in hydroxide media and thus the higher hydrophobicity of the former might be beneficial in order to prevent degradation due to excessive contact with water. However, the BEA framework has already been shown to be less stable than MFI even in the absence of 70 water.[171] Moreover, a negative role by the chelating properties of biobased substrates have been claimed but not studied in depth. The likely restructuring of the metal species due to the action of the medium and/or the molecules involved in the transformations might actually minimise the differences in metal 75 speciation associated with distinct frameworks and/or preparation routes under reaction conditions. Generally, metal leaching should not be excluded only based on good catalyst recyclability in batch tests (typically performed at equilibrium) or on positive indications by hot filtration tests (leached species might be 80 inactive for the reaction under study) but through elemental analysis of the solid or the reaction mixture. Possibly, the materials should be better evaluated under continuous-flow conditions. This type of operation not only is more convenient to identify deactivation but also is most desired for the production of 85 chemicals at an industrial scale.

Finally, it would be interesting to assess the possibility to extrapolate these new classes of materials to other relevant applications of Lewis-acid catalysis, such as Friedel-Crafts reactions, which have been duly reviewed by Corma and ${ }_{90}$ Garcia.[172]

\section{Acknowledgments}

This work was supported by the Swiss National Science Foundation (Project Number 200021-140496). The authors thank T. C. Keller for the help with the graphical illustrations.

\section{${ }_{95}$ Notes and references}

Institute for Chemical and Bioengineering, Department of Chemistry and Applied Biosciences, ETH Zurich, Vladimir-Prelog-Weg 1, CH-8093 Zurich, Switzerland

jpr@chem.ethz.ch; Fax: +41 44 6331405; Tel: +41 446337120.

100 1. D. M. Alonso, J. Q. Bond and J. A. Dumesic, Green Chem., 2010, 12, 1493-1513.

2. M. Besson, P. Gallezot and C. Pinel, Chem. Rev., 2013, 114, 18271870 .

3. A. Corma, S. Iborra and A. Velty, Chem. Rev., 2007, 107, 2411-2502.

105 4. P. Y. Dapsens, C. Mondelli and J. Pérez-Ramírez, ACS Catal., 2012, 2, 1487-1499.

5. G. W. Huber, S. Iborra and A. Corma, Chem. Rev., 2006, 106, 40444098.

6. F. Cherubini, Energy Convers. Manage., 2010, 51, 1412-1421.

110 7. P. C. A. Bruijnincx and B. M. Weckhuysen, Angew. Chem., Int. Ed., 2013, 52, 11980-11987.

8. M. Dusselier and B. F. Sels, Curr. Top. Catal., 2014, 353, 85-125. 
9. M. Dusselier, P. Van Wouwe, A. Dewaele, E. Makshina and B. F. Sels, Energy Environ. Sci., 2013, 6, 1415-1442.

10. S. Munoz-Guerra, C. Lavilla, C. Japu and A. Martinez de Ilarduya, Green Chem., 2014, 16, 1716-1739.

5 11. R. A. Sheldon, Green Chem., 2014, 16, 950-963.

12. S. Thiyagarajan, W. Vogelzang, R. J. I. Knoop, A. E. Frissen, J. van Haveren and D. S. van Es, Green Chem., 2014, 16, 1957-1966.

13. C. Vilela, A. F. Sousa, A. C. Fonseca, A. C. Serra, J. F. J. Coelho, C. S. R. Freire and A. J. D. Silvestre, Polym. Chem., 2014, 5, 3119-

$10 \quad 3141$.

14. R. Rinaldi and F. Schuth, Energy Environ. Sci., 2009, 2, 610-626.

15. V. Valtchev, G. Majano, S. Mintova and J. Perez-Ramirez, Chem. Soc. Rev., 2013, 42, 263-290.

16. E. Taarning, C. M. Osmundsen, X. Yang, B. Voss, S. I. Andersen 15 and C. H. Christensen, Energy Environ. Sci., 2011, 4, 793-804.

17. P. A. Jacobs, M. Dusselier and B. F. Sels, Angew. Chem., Int. Ed., 2014, 53, 8621-8626.

18. C. M. Osmundsen, M. S. Holm, S. Dahl and E. Taarning, Proc. $R$. Soc. A, 2012, 468, 2000-2016.

20 19. Y. Román-Leshkov and M. E. Davis, ACS Catal., 2011, 1, 15661580.

20. R. Gounder, Catal. Sci. Technol., 2014, 4, 2877-2886.

21. S. Li, A. Zheng, Y. Su, H. Zhang, L. Chen, J. Yang, C. Ye and F. Deng, J. Am. Chem. Soc., 2007, 129, 11161-11171.

25 22. A. Primo and H. Garcia, Chem. Soc. Rev., 2014, 43, 7548-7561.

23. M. Taramasso, G. Perego and B. Notari, US Pat. 4410501, 1983.

24. G. Peregot, G. Bellussi, C. Corno, M. Taramasso, F. Buonomot and A. Esposito, Stud. Surf. Sci. Catal., 1986, 28, 129-136.

25. M. Moliner, Dalton Trans., 2014, 43, 4197-4208.

30 26. E. M. Flanigen and R. L. Patton, US Pat. 4073865, 1978.

27. M. A. Camblor, A. Corma and S. Valencia, Chem. Commun., 1996, 2365-2366.

28. M. Moliner and A. Corma, Microporous Mesoporous Mater., 2014, 189, 31-40.

35 29. N. K. Mal, V. Ramaswamy, S. Ganapathy and A. V. Ramaswamy, Chem. Commun., 1994, 1933-1934.

30. N. K. Mal, V. Ramaswamy, P. R. Rajamohanan and A. V. Ramaswamy, Microporous Mater., 1997, 12, 331-340.

31. M. Costantini, J. L. Guth, A. Lopez and J.-M. Popa, EU Pat. $40 \quad 0466545,1992$.

32. P. Y. Dapsens, C. Mondelli, B. T. Kusema, R. Verel and J. PerezRamirez, Green Chem., 2014, 16, 1176-1186.

33. M. Morales, P. Y. Dapsens, I. Giovinazzo, J. Witte, C. Mondelli, S. Papadokonstantakis, K. Hungerbuhler and J. Perez-Ramirez, Energy

45 Environ. Sci., 2015, 8, 558-567.

34. J. Perez-Pariente, J. A. Martens and P. A. Jacobs, Zeolites, 1988, 8, 46-53.

35. T. J. Schwartz, S. M. Goodman, C. M. Osmundsen, E. Taarning, M. D. Mozuch, J. Gaskell, D. Cullen, P. J. Kersten and J. A. Dumesic, 50 ACS Catal., 2013, 3, 2689-2693.

36. P. Wolf, C. Hammond, S. Conrad and I. Hermans, Dalton Trans., 2014, 43, 4514-4519.

37. C. M. Lew, N. Rajabbeigi and M. Tsapatsis, Microporous Mesoporous Mater., 2012, 153, 55-58.
55 38. E. Taarning, S. Saravanamurugan, M. Spangsberg Holm, J. Xiong, R. M. West and C. H. Christensen, ChemSusChem, 2009, 2, 625627.

39. Q. Guo, F. Fan, E. A. Pidko, W. N. P. van der Graaff, Z. Feng, C. Li and E. J. M. Hensen, ChemSusChem, 2013, 6, 1352-1356.

60 40. R. M. West, M. S. Holm, S. Saravanamurugan, J. Xiong, Z. Beversdorf, E. Taarning and C. H. Christensen, J. Catal., 2010, 269, 122-130.

41. P. Y. Dapsens, C. Mondelli and J. Pérez-Ramírez, ChemSusChem, 2013, 6, 831-839.

65 42. C. Hammond, S. Conrad and I. Hermans, Angew. Chem., Int. Ed., 2012, 51, 11736-11739.

43. J. Dijkmans, M. Dusselier, D. Gabriëls, K. Houthoofd, P. C. M. M. Magusin, S. Huang, Y. Pontikes, M. Trekels, A. Vantomme, L. Giebeler, S. Oswald and B. F. Sels, ACS Catal., 2015, 5, 928-940.

70 44. W. N. P. van der Graaff, G. Li, B. Mezari, E. A. Pidko and E. J. M. Hensen, ChemCatChem, 2015, DOI: 10.1002/cctc.201403050.

45. P. P. Pescarmona, K. P. F. Janssen, C. Delaet, C. Stroobants, K. Houthoofd, A. Philippaerts, C. De Jonghe, J. S. Paul, P. A. Jacobs and B. F. Sels, Green Chem., 2010, 12, 1083-1089.

75 46. P. Y. Dapsens, B. T. Kusema, C. Mondelli and J. Pérez-Ramírez, J. Mol. Catal. A: Chem., 2014, 388-389, 141-147.

47. K. Lin, L. Li, B. F. Sels, P. A. Jacobs and P. P. Pescarmona, Catal. Today, 2011, 173, 89-94.

48. S. Saravanamurugan and A. Riisager, Catal. Sci. Technol., 2014, 4, 3186-3190.

49. W. R. Gunther, Y. Wang, Y. Ji, V. K. Michaelis, S. T. Hunt, R. G. Griffin and Y. Román-Leshkov, Nat. Commun., 2012, 3, 1109.

50. V. Choudhary, A. B. Pinar, S. I. Sandler, D. G. Vlachos and R. F. Lobo, ACS Catal., 2011, 1, 1724-1728.

85 51. P. Y. Dapsens, C. Mondelli, J. Jagielski, R. Hauert and J. PerezRamirez, Catal. Sci. Technol., 2014, 4, 2302-2311.

52. H. J. Cho, P. Dornath and W. Fan, ACS Catal., 2014, 4, 2029-2037.

53. M. Paniagua, S. Saravanamurugan, M. Melian-Rodriguez, J. A. Melero and A. Riisager, ChemSusChem, 2015, 8, 1088-1094.

90 54. J. Dijkmans, D. Gabriels, M. Dusselier, F. de Clippel, P. Vanelderen, K. Houthoofd, A. Malfliet, Y. Pontikes and B. F. Sels, Green Chem., 2013, 15, 2777-2785.

55. M. Moliner, Y. Román-Leshkov and M. E. Davis, Proc. Natl. Acad. Sci. U. S. A., 2010, 107, 6164-6168.

95 56. Y. Román-Leshkov, M. Moliner, J. A. Labinger and M. E. Davis, Angew. Chem., Int. Ed., 2010, 49, 8954-8957.

57. R. Bermejo-Deval, R. S. Assary, E. Nikolla, M. Moliner, Y. RománLeshkov, S.-J. Hwang, A. Palsdottir, D. Silverman, R. F. Lobo, L. A. Curtiss and M. E. Davis, Proc. Natl. Acad. Sci. U. S. A., 2012, 109, 9727-9732.

58. R. Gounder and M. E. Davis, J. Catal., 2013, 308, 176-188.

59. N. Rajabbeigi, A. I. Torres, C. M. Lew, B. Elyassi, L. Ren, Z. Wang, H. Je Cho, W. Fan, P. Daoutidis and M. Tsapatsis, Chem. Eng. Sci., 2014, 116, 235-242.

10560 . C.-C. Chang, H. J. Cho, Z. Wang, X. Wang and W. Fan, Green Chem., 2015, DOI: 10.1039/C1034GC02457E.

61. S. Saravanamurugan, M. Paniagua, J. A. Melero and A. Riisager, $J$. Am. Chem. Soc., 2013, 135, 5246-5249.

62. H. J. Cho, C.-C. Chang and W. Fan, Green Chem., 2014, 16, $3428-$ 3433. 
63. R. Bermejo-Deval, R. Gounder and M. E. Davis, ACS Catal., 2012, 2, 2705-2713.

64. R. Bermejo-Deval, M. Orazov, R. Gounder, S.-J. Hwang and M. E. Davis, ACS Catal., 2014, 4, 2288-2297.

5 65. W. R. Gunther, Q. Duong and Y. Román-Leshkov, J. Mol. Catal. A: Chem., 2013, 379, 294-302.

66. R. Gounder and M. E. Davis, ACS Catal., 2013, 3, 1469-1476.

67. M. S. Holm, S. Saravanamurugan and E. Taarning, Science, 2010, 328, 602-605.

10 68. M. S. Holm, Y. J. Pagan-Torres, S. Saravanamurugan, A. Riisager, J. A. Dumesic and E. Taarning, Green Chem., 2012, 14, 702-706.

69. S. Tolborg, I. Sádaba, C. M. Osmundsen, P. Fristrup, M. S. Holm and E. Taarning, ChemSusChem, 2015, 8, 613-617.

70. S. Van de Vyver, C. Odermatt, K. Romero, T. Prasomsri and Y.

15 Román-Leshkov, ACS Catal., 2015, 5, 972-977.

71. J. Jae, E. Mahmoud, R. F. Lobo and D. G. Vlachos, ChemCatChem, 2014, 6, 508-513.

72. J. D. Lewis, S. Van de Vyver, A. J. Crisci, W. R. Gunther, V. K. Michaelis, R. G. Griffin and Y. Román-Leshkov, ChemSusChem, $202014,7,2255-2265$.

73. L. Bui, H. Luo, W. R. Gunther and Y. Román-Leshkov, Angew. Chem., Int. Ed., 2013, 52, 8022-8025.

74. H. Y. Luo, D. F. Consoli, W. R. Gunther and Y. Román-Leshkov, J. Catal., 2014, 320, 198-207.

25 75. J. J. Pacheco and M. E. Davis, Proc. Natl. Acad. Sci. U. S. A., 2014, 111, 8363-8367.

76. N. K. Mal and A. V. Ramaswamy, Chem. Commun., 1997, 425-426.

77. J. C. van der Waal, M. S. Rigutto and H. van Bekkum, Chem. Commun., 1994, 1241-1242.

30 78. A. Corma, L. T. Nemeth, M. Renz and S. Valencia, Nature, 2001, 412, 423-425.

79. S. Tolborg, A. Katerinopoulou, D. D. Falcone, I. Sadaba, C. M. Osmundsen, R. J. Davis, E. Taarning, P. Fristrup and M. S. Holm, J. Mater. Chem. A, 2014, 2, 20252-20262.

35 80. N. Kishor Mal, V. Ramaswamy, S. Ganapathy and A. V. Ramaswamy, Appl. Catal., A, 1995, 125, 233-245.

81. N. K. Mal, A. Bhaumik, R. Kumar and A. V. Ramaswamy, Catal Lett, 1995, 33, 387-394.

82. D. M. Bibby, N. B. Milestone and L. P. Aldridge, Nature, 1979, $40 \quad$ 280, 664-665.

83. E. G. Rosinki and M. K. Rubin, US Pat. 3832449, 1974.

84. J. Perez-Ramirez, Nat. Chem., 2012, 4, 250-251.

85. J. Karger and R. Valiullin, Chem. Soc. Rev., 2013, 42, 4172-4197.

86. D. P. Serrano, J. M. Escola and P. Pizarro, Chem. Soc. Rev., 2013, $45 \quad$ 42, 4004-4035.

87. W. J. Roth, P. Nachtigall, R. E. Morris and J. Čejka, Chem. Rev., 2014, 114, 4807-4837.

88. I. I. Ivanova and E. E. Knyazeva, Chem. Soc. Rev., 2013, 42, 36713688.

50 89. K. Moller and T. Bein, Chem. Soc. Rev., 2013, 42, 3689-3707.

90. W. Fan, M. A. Snyder, S. Kumar, P.-S. Lee, W. C. Yoo, A. V. McCormick, R. Lee Penn, A. Stein and M. Tsapatsis, Nat. Mater., 2008, 7, 984-991.

91. H. Chen, J. Wydra, X. Zhang, P.-S. Lee, Z. Wang, W. Fan and M.

55 Tsapatsis, J. Am. Chem. Soc., 2011, 133, 12390-12393.
92. H. Y. Luo, L. Bui, W. R. Gunther, E. Min and Y. Román-Leshkov, ACS Catal., 2012, 2, 2695-2699.

93. M. Choi, K. Na, J. Kim, Y. Sakamoto, O. Terasaki and R. Ryoo, Nature, 2009, 461, 246-249.

60 94. M. Matsukata, M. Ogura, T. Osaki, P. Hari Prasad Rao, M. Nomura and E. Kikuchi, Top. Catal., 1999, 9, 77-92.

95. W. Xu, J. Dong, J. Li, J. Li and F. Wu, Chem. Commun., 1990, $755-$ 756.

96. P. S. Niphadkar, M. S. Kotwal, S. S. Deshpande, V. V. Bokade and 65 P. N. Joshi, Mater. Chem. Phys., 2009, 114, 344-349.

97. Z. Kang, X. Zhang, H. Liu, J. Qiu and K. L. Yeung, Chem. Eng. J., 2013, 218, 425-432.

98. T. Yashima, Catal. Surv. Asia, 1998, 2, 121-132.

99. H. K. Beyer and I. Belenykaja, Stud. Surf. Sci. Catal., 1980, 5, 203$70 \quad 210$.

100. C. D. Chang, C. T. W. Chu, J. N. Miale, R. F. Bridger and R. B. Calvert, J. Am. Chem. Soc., 1984, 106, 8143-8146.

101. R. M. Dessau and G. T. Kerr, Zeolites, 1984, 4, 315-318.

102. K. Yamagishi, S. Namba and T. Yashima, J. Catal., 1990, 121, $47-$ $75 \quad 55$.

103. T. Yashima, K. Yamagishi and S. Namba, Stud. Surf. Sci. Catal., 1991, 60, 171-178.

104. G. W. Skeels, D. M. Chapman and F. E.M., US pat. 5401488, 1995.

105. B. D. Vandegehuchte, J. W. Thybaut, C. Detavernier, D. Deduytsche, J. Dendooven, J. A. Martens, S. P. Sree, T. I. Korányi and G. B. Marin, J. Catal., 2014, 311, 433-446.

106. E. Verheyen, S. Pulinthanathu Sree, K. Thomas, J. Dendooven, M. De Prins, G. Vanbutsele, E. Breynaert, J. P. Gilson, C. E. A. Kirschhock, C. Detavernier and J. A. Martens, Chem. Commun., 2014, 50, 4610-4612.

107. C. Detavernier, J. Dendooven, S. Pulinthanathu Sree, K. F. Ludwig and J. A. Martens, Chem. Soc. Rev., 2011, 40, 5242-5253.

108. J. A. Martens, D. Deduytsche, C. Detavernier and S. Pulinthanathu Sree, US Pat. 8673804, 2014.

90 109. K.-J. Chao and P.-H. Liu, Catal. Surv. Asia, 2005, 9, 11-15.

110. M. García-Sánchez, P. C. M. M. Magusin, E. J. M. Hensen, P. C. Thüne, X. Rozanska and R. A. van Santen, J. Catal., 2003, 219, 352-361.

111. N. Rane, A. R. Overweg, V. B. Kazansky, R. A. van Santen and E. 95 J. M. Hensen, J. Catal., 2006, 239, 478-485.

112. G. M. Zhidomirov, A. A. Shubin, M. A. Milov, V. B. Kazansky, R. A. van Santen and E. J. M. Hensen, J. Phys. Chem. C, 2008, 112, 3321-3326.

113. A. Bhan and W. Nicholas Delgass, Catal. Rev.: Sci. Eng., 2008, 50, 19-151.

114. E. A. Pidko, R. A. van Santen and E. J. M. Hensen, Phys. Chem. Chem. Phys., 2009, 11, 2893-2902.

115. V. d. O. Rodrigues, J.-G. Eon and A. C. Faro, J. Phys. Chem. C, 2010, 114, 4557-4567.

105 116. N. Al-Yassir, M. N. Akhtar and S. Al-Khattaf, J. Porous Mater., 2012, 19, 943-960.

117. J. A. Biscardi, G. D. Meitzner and E. Iglesia, J. Catal., 1998, 179, 192-202.

118. A. Smiešková, E. Rojasová, P. Hudec and L. Šabo, Appl. Catal., A, 2004, 268, 235-240. 
119. A. Smiešková, E. Rojasová, P. Hudec and L. Šabo, React. Kinet. Catal. Lett., 2004, 82, 227-234.

120. E. A. Pidko and R. A. van Santen, J. Phys. Chem. C, 2007, 111, 2643-2655.

5 121. S. M. T. Almutairi, B. Mezari, P. C. M. M. Magusin, E. A. Pidko and E. J. M. Hensen, ACS Catal., 2012, 2, 71-83.

122. B. Kraushaar and J. H. C. Van Hooff, Catal Lett, 1988, 1, 81-84.

123. P. Wu, T. Komatsu and T. Yashima, J. Phys. Chem., 1996, 100, 10316-10322.

10 124. P. Wu, T. Komatsu, T. Yashima, S.-i. Nakata and H. Shouji, Microporous Mater., 1997, 12, 25-37.

125. M. S. Rigutto, R. de Ruiter, J. P. M. Niederer and H. van Bekkum, Stud. Surf. Sci. Catal., 1994, 84, 2245-2252.

126. P. Li, G. Liu, H. Wu, Y. Liu, J.-g. Jiang and P. Wu, J. Phys. Chem.

15 C, 2011, 115, 3663-3670.

127. M. Liu, S. Jia, C. Li, A. Zhang, C. Song and X. Guo, Chin. J. Catal., 2014, 35, 723-732.

128. J. Jin, X. Ye, Y. Li, Y. Wang, L. Li, J. Gu, W. Zhao and J. Shi, Dalton Trans., 2014, 43, 8196-8204.

20 129. B. Tang, W. Dai, X. Sun, N. Guan, L. Li and M. Hunger, Green Chem., 2014, 16, 2281-2291.

130. B. Tang, W. Dai, G. Wu, N. Guan, L. Li and M. Hunger, ACS Catal., 2014, 4, 2801-2810.

131. B. Tang, W. Dai, X. Sun, G. Wu, N. Guan, M. Hunger and L. Li,

25 Green Chem., 2015, 17, 1744-1755.

132. J. Wang, K. Okumura, S. Jaenicke and G.-K. Chuah, Appl. Catal., A, 2015, 493, 112-120.

133. D. Verboekend and J. Perez-Ramirez, Catal. Sci. Technol., 2011, 1, 879-890.

30 134. M. Milina, S. Mitchell, N.-L. Michels, J. Kenvin and J. PérezRamírez, J. Catal., 2013, 308, 398-407.

135. J. Pérez-Ramírez, S. Mitchell, D. Verboekend, M. Milina, N.-L. Michels, F. Krumeich, N. Marti and M. Erdmann, ChemCatChem, 2011, 3, 1731-1734.

35 136. M. R. Boccuti, K. M. Rao, A. Zecchina, G. Leofanti and G. Petrini, Stud. Surf. Sci. Catal., 1989, 48, 133-144.

137. J. Klaas, K. Kulawik, G. Schulz-Ekloff and N. I. Jaeger, Stud. Surf. Sci. Catal., 1994, 84, 2261-2268.

138. F. C. Jentoft, Adv. Catal., 2009, 52, 129-211.

40 139. N. K. Mal and A. V. Ramaswamy, J. Mol. Catal. A: Chem., 1996, 105, 149-158.

140. K. A. Genov, Ph.D. Thesis, University of Bremen, 2004.

141. A. de Kergommeaux, J. Faure-Vincent, A. Pron, R. de Bettignies, B. Malaman and P. Reiss, J. Am. Chem. Soc., 2012, 134, 11659-11666.

45 142. K. Lázár, A. M. Szeleczky, N. K. Mal and A. V. Ramaswamy, Zeolites, 1997, 19, 123-127.

143. P. Wolf, M. Valla, A. J. Rossini, A. Comas-Vives, F. Núñez-Zarur, B. Malaman, A. Lesage, L. Emsley, C. Copéret and I. Hermans, Angew. Chem., Int. Ed., 2014, 53, 10179-10183.

50 144. W. R. Gunther, V. K. Michaelis, M. A. Caporini, R. G. Griffin and Y. Román-Leshkov, J. Am. Chem. Soc., 2014, 136, 6219-6222.

145. R. Millini, E. Previde Massara, G. Perego and G. Bellussi, J. Catal., 1992, 137, 497-503.

146. C. Lamberti, S. Bordiga, A. Zecchina, A. Carati, A. N. Fitch, G.

55 Artioli, G. Petrini, M. Salvalaggio and G. L. Marra, J. Catal., 1999, 183, 222-231.
147. M. A. Camblor, A. Corma, A. Martínez, J. Pérez-Pariente and J. Primo, Stud. Surf. Sci. Catal., 1993, 78, 393-399.

148. D. Scarano, A. Zecchina, S. Bordiga, F. Geobaldo, G. Spoto, G.

60 Petrini, G. Leofanti, M. Padovan and G. Tozzola, Faraday Trans., 1993, 89, 4123-4130.

149. C. Li, G. Xiong, J. Liu, P. Ying, Q. Xin and Z. Feng, J. Phys. Chem. B, 2001, 105, 2993-2997.

150. T. D. Courtney, C.-C. Chang, R. J. Gorte, R. F. Lobo, W. Fan and 65 V. Nikolakis, Microporous Mesoporous Mater., 2015, 210, 69-76.

151. G. L. Marra, G. Artioli, A. N. Fitch, M. Milanesio and C. Lamberti, Microporous Mesoporous Mater., 2000, 40, 85-94.

152. C. A. Hijar, R. M. Jacubinas, J. Eckert, N. J. Henson, P. J. Hay and K. C. Ott, J. Phys. Chem. B, 2000, 104, 12157-12164.

70 153. P. F. Henry, M. T. Weller and C. C. Wilson, J. Phys. Chem. B, 2001, 105, 7452-7458.

154. S. R. Bare, S. D. Kelly, W. Sinkler, J. J. Low, F. S. Modica, S. Valencia, A. Corma and L. T. Nemeth, J. Am. Chem. Soc., 2005, 127, 12924-12932.

75 155. M. Boronat, P. Concepción, A. Corma, M. Renz and S. Valencia, $J$. Catal., 2005, 234, 111-118.

156. A. I. Biaglow, C. Gittleman, R. J. Gorte and R. J. Madon, J. Catal., 1991, 129, 88-93.

157. R. J. Gorte, Catal Lett, 1999, 62, 1-13.

80 158. S. Roy, K. Bakhmutsky, E. Mahmoud, R. F. Lobo and R. J. Gorte, ACS Catal., 2013, 3, 573-580.

159. Y. Seo, K. Cho, Y. Jung and R. Ryoo, ACS Catal., 2013, 3, $713-$ 720.

160. A. Zheng, S.-J. Huang, S.-B. Liu and F. Deng, Phys. Chem. Chem.

85 Phys., 2011, 13, 14889-14901.

161. J. H. Lunsford, W. P. Rothwell and W. Shen, J. Am. Chem. Soc., 1985, 107, 1540-1547.

162. Q. Zhao, W.-H. Chen, S.-J. Huang, Y.-C. Wu, H.-K. Lee and S.-B. Liu, J. Phys. Chem. B, 2002, 106, 4462-4469.

90 163. S. Shetty, B. S. Kulkarni, D. G. Kanhere, A. Goursot and S. Pal, J. Phys. Chem. B, 2008, 112, 2573-2579.

164. G. Yang, E. A. Pidko and E. J. M. Hensen, J. Phys. Chem. C, 2013, 117, 3976-3986.

165. G. Yang, E. A. Pidko and E. J. M. Hensen, ChemSusChem, 2013, 6, $95 \quad 1688-1696$

166. G. Li, E. A. Pidko and E. J. M. Hensen, Catal. Sci. Technol., 2014, 4, 2241-2250.

167. N. Rai, S. Caratzoulas and D. G. Vlachos, ACS Catal., 2013, 3, 2294-2298.

100 168. Y.-P. Li, M. Head-Gordon and A. T. Bell, ACS Catal., 2014, 4, 1537-1545.

169. R. S. Assary and L. A. Curtiss, J. Phys. Chem. A, 2011, 115, 87548760.

170. B. K. Chethana and S. H. Mushrif, J. Catal., 2015, 323, 158-164.

105 171. A. Carati, C. Flego, E. Previde Massara, R. Millini, L. Carluccio, W. O. Parker Jr and G. Bellussi, Microporous Mesoporous Mater., 1999, 30, 137-144.

172. A. Corma and H. García, Chem. Rev., 2003, 103, 4307-4366. 